\title{
Myeloid Immune Cells CARrying a New Weapon Against Cancer
}

\begin{abstract}
Rodrigo Nalio Ramos ${ }^{1,2 *}$, Samuel Campanelli Freitas Couto ${ }^{1,3}$, Theo Gremen M. Oliveira ${ }^{1,3}$, Paulo Klinger ${ }^{1}$, Tarcio Teodoro Braga ${ }^{4,5}$, Eduardo Magalhães Rego ${ }^{1,2}$, José Alexandre M. Barbuto ${ }^{1,6}$ and Vanderson Rocha ${ }^{1,2,3,7}$

${ }^{1}$ Laboratory of Medical Investigation in Pathogenesis and Directed Therapy in Onco-Immuno-Hematology (LIM-31), Departament of Hematology and Cell Therapy, Hospital das Clínicas HCFMUSP, Faculdade de Medicina, University of São Paulo, São Paulo, Brazil, 'Instituto D'Or de Ensino e Pesquisa, São Paulo, Brazil, ${ }^{3}$ Fundação Pró-Sangue-Hemocentro de São Paulo, São Paulo, Brazil, ${ }^{4}$ Department of Pathology, Federal University of Parana, Curitiba, Brazil, ${ }^{5}$ Graduate Program in Biosciences and Biotechnology, Instituto Carlos Chagas, Fiocruz-Parana, Curitiba, Brazil, ${ }^{6}$ Departamento de Imunologia, Instituto de CienciasBiomedicas, Universidade de Sao Paulo, São Paulo, Brazil, ${ }^{7}$ Churchill Hospital, Department of Hematology, University of Oxford, Oxford, United Kingdom
\end{abstract}

Chimeric antigen receptor (CAR) engineering for T cells and natural killer cells (NK) are now under clinical evaluation for the treatment of hematologic cancers. Although encouraging clinical results have been reported for hematologic diseases, pre-clinical studies in solid tumors have failed to prove the same effectiveness. Thus, there is a growing interest of the scientific community to find other immune cell candidate to express CAR for the treatment of solid tumors and other diseases. Mononuclear phagocytes may be the most adapted group of cells with potential to overcome the dense barrier imposed by solid tumors. In addition, intrinsic features of these cells, such as migration, phagocytic capability, release of soluble factors and adaptive immunity activation, could be further explored along with gene therapy approaches. Here, we discuss the elements that constitute the tumor microenvironment, the features and advantages of these cell subtypes and the latest studies using CAR-myeloid immune cells in solid tumor models.

\footnotetext{
Keywords: CAR (chimeric antigen receptor), monocyte, myeloid cells, solid tumor (malignancy and long term complications), macrophages, dendritic cell (DC)
}

\section{INTRODUCTION}

The myeloid immune cell compartment is composed by distinct cell subtypes that present a variety of functions once they have differentiated and maturated at the periphery. Within this compartment, besides the other cell types, the mononuclear phagocyte cells include subsets of monocytes, macrophages and dendritic cells (DC).

Monocytes are mostly found in the blood and macrophages are exclusively found in the tissues, while DC subsets can be found both in circulation and tissues.

Many phenotypic characteristics of DC associated with the induction of various T-cell response patterns have been described. It allows, for example, the association of the conventional Dendritic Cell 1 ( $\mathrm{cDC} 1$ ) phenotype with the induction of CD8+ cytotoxic T lymphocytes (CTL) (Bachem et al., 2010), the conventional Dendritic Cell 2 (cDC2) phenotype with that of various Th subtypes (Segura et al., 2005; Rojas et al., 2017) but also of Treg cells (Watchmaker et al., 2014), while the plasmacytoid Dendritic Cell (pDC) phenotype has been mostly associated with the production of type I interferon (Reizis et al., 2011). However, this is 
an incomplete picture which is quickly being filled outand much still needs to be determined before one can predict the in vivo response from any DC phenotype introduced in the system.

Most recently, distinct groups have described other DC subset such as inflammatory-DCs (Segura et al., 2013) and type 3 DC (DC3) (Dutertre et al., 2019; Bourdely et al., 2020).

Several studies have highlighted the critical role of myeloid immune cells during tumor growth and metastasis, as reviewed by Engblom and collaborators (Engblom et al., 2016). Collective findings have put evidence on the association of tumor-associated macrophages (TAMs) with poor patients' outcome for distinct tumor types (Medrek et al., 2012; Ino et al., 2013; Reinartz et al., 2014; Yang et al., 2018; Ramos et al., 2020; Guo et al., 2021). In contrast, mature DC subsets are currently associated to good prognosis, mostly due to their anti-tumoral role by stimulating T cell responses (Ladányi et al., 2007; Goc et al., 2014; Truxova et al., 2018). Also, an important role of type I IFNs has been discussed as being critical for the innate and adaptive immunity cross-talk (Demaria et al., 2019). Nucleic-acid-sensing cytosolic receptors, such as cGAS-STING pathways, found in the tumor microenvironment may trigger the production of type I IFNs that promote activation of NK cells, which subsequently stimulate DCs and T lymphocytes and anti-tumoral responses.

Numerous studies have reported the use of distinct strategies to overcome the immunosuppressive tumor microenvironment via the stimulation of myeloid immune cells (Chaib et al., 2020; Neophytou et al., 2020). These approaches include: the recruitment of a new wave of immune cells; the stimulation of cells via agonists/ligands; cytokine-based treatments; blockage of receptors by monoclonal antibodies and drug-mediated reprogramming of cells.

Very recently, some reports have described the insertion of chimeric antigen receptor (CAR) on macrophages (Klichinsky et al., 2020; Morrissey et al., 2018; W. Zhang et al., 2019; Zhang L. et al., 2020), an already known technology used for T cells (CAR$\mathrm{T}$ ) and natural killer cells (CAR-NK). CAR-T and CAR-NK cell therapies have achieved encouraging results in hematological tumors (Waldman et al., 2020). There has been a rapid growth of published data associated with CAR-T cells. Around 700 active clinical trials can be found at ClinicalTrials.gov database using CAR-T as a treatment modality. Most studies focus on hematologic malignancies, while 45 studies are related to solid tumor treatment. The inherent cytotoxicity of natural killer (NK) cells against tumors and their potential as an "off-the-shelf" cell therapy product have encouraged several clinical trials using CAR expressing NK cells to treat a number of malignant diseases (Xie et al., 2020). There are currently 19 active CAR-NK registered clinical trials, most of them targeting CD19+ hematological malignancies.

The myeloid lineages, especially the mononuclear phagocyte system, present an auspicious future, considering their functional capacity, which includes phagocytosis, antigen presentation, $\mathrm{T}$ cell co-stimulation, extracellular matrix remodeling and infiltration into the tumor microenvironment (Anderson et al., 2021; Chen et al., 2021). Despite technical issues concerning transfection, gene delivery and stable expression of CAR on myeloid immune cells (Dokka et al., 2000; Stroh et al., 2010; Keller et al., 2018), preliminary in vitro and pre-clinical results using CAR-Macrophages (CAR-Mac) have shown exciting data. We discuss here some important features of monocytes, DCs and macrophages for cancer therapy and the newly reported studies engineering myeloid cells to express CAR.

\section{ONTOGENY OF MYELOID IMMUNE CELLS}

The mononuclear phagocyte system was originally described as bone marrow-derived myeloid cells that circulate in the blood as monocytes and reside in tissues as macrophages in both the steady state and inflammation (Furth and Cohn 1968). It is now known that different progenitors can give rise to several cell subsets with distinct phenotypes and particular biological functions. Additionally, migration to tissues and the differentiation of lineage-committed progenitors might be influenced by the surrounding microenvironment such as the inflammatory milieu (Serbina et al., 2008). Monocytes respond to their environment by differentiating into a variety of macrophages and DC-like cells to mount specific functional programs (Taylor and Gordon 2003). The generation and development of monocytes, macrophages and DCs is driven by the association of specific cytokines and growth factors with receptors expressed in hematopoietic stem cell-derived precursors (Sasmono et al., 2003). The bone marrow-derived progenitors are responsible for the renewal of a substantial set of myeloid cells, although many tissue-resident macrophages and DCs subsets (microglia and Langerhans cells) seem to be able to self-renewal, and, thus, independent of this developmental pathway (Ajami et al., 2007; Merad and Manz 2009).

The first myeloid cells originate from hematopoietic progenitors in the human yolk sac at 2 to 3 weeks post conception (Ginhoux and Jung 2014; Epelman et al., 2014). Primitive hematopoietic stem cells (HSCs) enter the circulation and seed the fetal liver, giving rise to the first population of granulocyte-monocyte progenitors (GMPs) and blood monocytes (Hoeffel and Ginhoux 2015; Hoeffel et al., 2015). Under inflammatory conditions, monocytes exit to the blood and enter tissues, giving rise to subsets of macrophages and to inflammatory DCs (Auffray et al., 2009). It is noteworthy that monocytes do not give rise to $\mathrm{CDCs}$ and $\mathrm{pDCs}$ but are the main contributors of monocyte-derived DCs (Mo-DCs) during inflammation (Coillard and Segura 2019). Alternatively, commitment to the human $\mathrm{cDC}$ lineage can occur in early lympho-myeloid progenitors, from multipotent lymphoid progenitors (MLPs) that can give rise to monocytes, pDCs and cDCs (Helft et al., 2017; Doulatov et al., 2010) (Figure 1). Most recently, distinct groups have described a third subset of DC (also called DC3) (Dutertre et al., 2019; Bourdely et al., 2020). DC3 usually present a mixed phenotypic and functional status, between that of monocytes and $\mathrm{CDC} 2$, and are differentiated from a distinct pre-DC3 progenitor in a GM-CSF dependentfashion. The DC3 subset closely resembles the monocyte-derived 


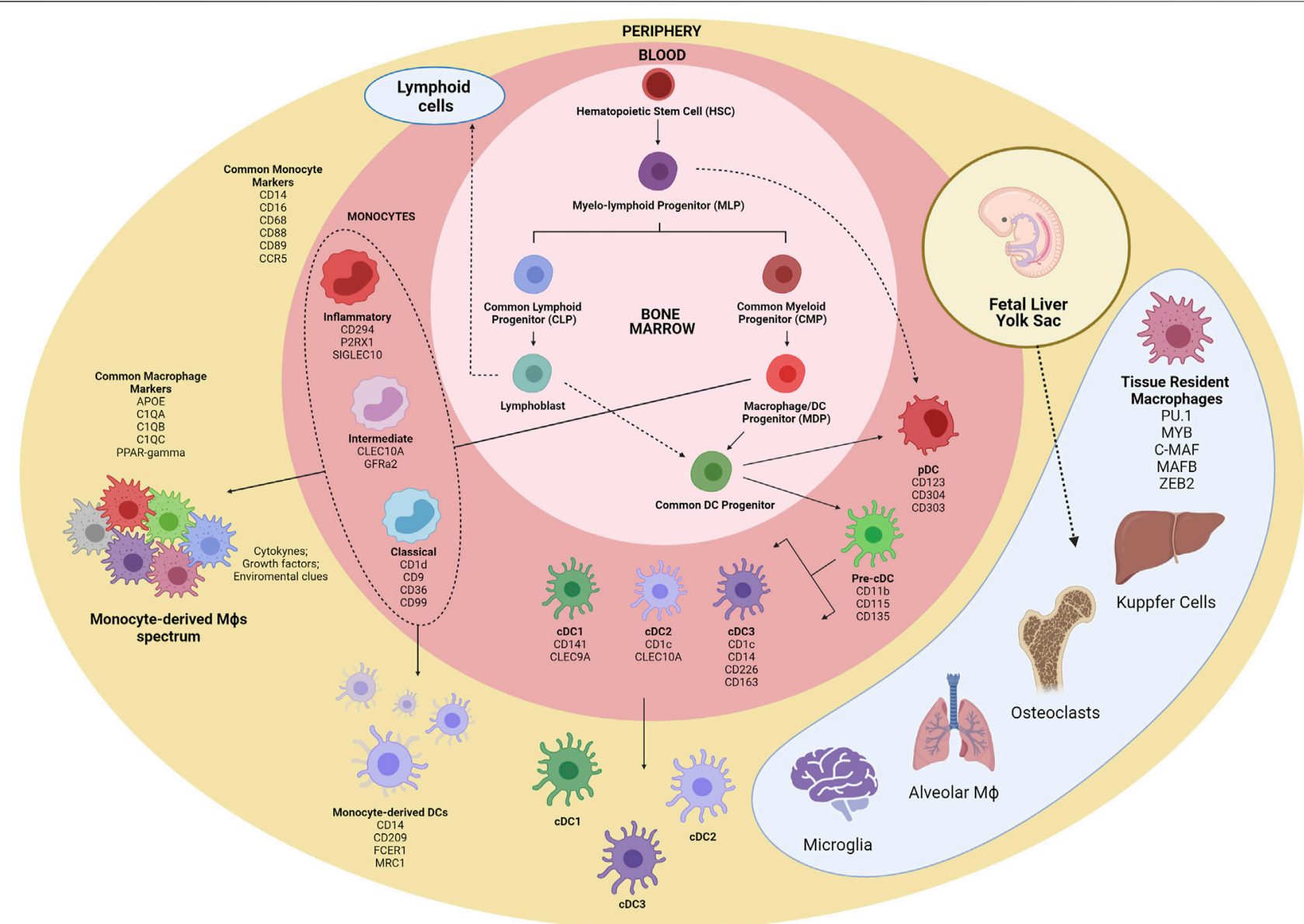

FIGURE 1|Schematic overview of myeloid cells ontogeny. The first myeloid cells arise in the embryonic phase from yolk sac-derived primitive HSCs and expand in the fetal liver, originating GMPs and blood monocytes. Tissue-resident macrophages are established before birth and are mostly repopulated by self-renewal. Within the bone marrow, CMPs give rise to GMPs and MDPs. MDPs are responsible for the contribution of many macrophages and DC subsets. MDPs differentiate into monocytes and CDPs, which in turn differentiate into $\mathrm{pDC}$ and pre-cDCs. Following exit from the BM, pre-cDCs enter peripheral organs and mature into cDC1, $\mathrm{cDC2}$, and cDC3. Alternatively, pDCs and cDCs may also originate from MLPs. Inflammatory cues contribute to monocyte migration to tissues, where they differentiate into macrophages and Mo-DCs. HSC, hematopoeticstem-cell; GMP, granulocyte-monocyte progenitor; CMP, common myeloid progenitor; MDP, macrophage/DC progenitor; MLP, myelo-lymphoid progenitor; CDP, common DC precursor; pre-cDC, precursor of classical DC; Mo-DC, monocyte-derived DC; $C D C$, classical DC; pDC, plasmacytoid DC.

dendritic cells, differentiated in vitro from blood monocytes, and normally accumulate under inflammatory conditions.

Several studies have been conducted to unravel the origin of the terminally differentiated cells of the mononuclear phagocyte system. The analysis of cell surface markers to separate different subpopulations of cells with myeloid origin has been shown to be very limited, since there is significant phenotypic overlap in the expression of cell surface markers among these cells (Guermonprez et al., 2019). Characteristic monocyte surface markers such as CD14, CD16, CD68, and CCR5 are shared with macrophages, and the expression of general macrophage specific surface markers (C1QC and VEGF) and tissue specific markers (VCAM1 and PPAR $\gamma$ ) are necessary for proper discrimination between monocytes and macrophages (Ginhoux and Jung 2014; Hoeffel and Ginhoux 2015).

Macrophage subsets could be further segregated into tissueresident and monocyte-derived cells. A great variety of tissue- resident macrophages are distributed in the human body presenting specialized functional features. Distinct studies have reported PU.1, MYB, C-MAF, MAF-B, and ZEB2 ascore transcriptional factors (TFs) shared by tissue-resident macrophages regardless of the tissue imprinting cues (Blériot et al., 2020). Under inflammatory conditions, intrinsic local signals as cytokines, growth factors, metabolites and others contribute for shaping the macrophage programing and function, generating a much more complex range of phenotypes.

The current DC classification can be quite troublesome, and there is still little consensus on the identification and naming of DC populations (Villar and Segura 2020). Nevertheless, there is a general consensus of classification of DCs into three main groups, based on their cellular and molecular ontogeny (Guilliams et al., 2014): 1) pDC; 2) conventional DC1 and DC2; and 3) DC3. The expression of the $\mathrm{CD} 123, \mathrm{CD} 304$, and CD303 surface markers defines pDCs, whereas $\mathrm{CD} 141$ and Clec9A are $\mathrm{CDC} 1$ specific 
markers, and expression of CD1c and CLEC10A seems to be restricted to $\mathrm{CDC} 2$. DC3/Mo-DCs share the expression of CD1c with $\mathrm{cDC} 2$, and $\mathrm{CD} 14$ with monocytes and macrophages, although they present specific subset markers, such as CD226 and CD163.

Studies on mice and in vitro culture of human cells have provided a better understanding of the developmental programs that seem to be hard-wired in hematopoietic progenitor cells to originate different myeloid cells (Epelman et al., 2014). These studies involved the selection of specific gene expression programs, including important TFs responsible for cell fate choices (Auffray et al., 2009; Merad and Manz 2009). The myeloid transcription factor PU.1 is required for the earliest steps of myeloid lineage commitment in HSCs (Sarrazin et al., 2009). This TF plays a role in myeloid lineage diversification, particularly during fate choice of monocytes into macrophage or DC (Bakri et al., 2005). The expression level of PU.1 in certain progenitor stages dictates the fate of a specific myeloid progenitor. Intermediate expression of PU.1 in GMPs favors differentiation to macrophages instead of granulocytes (Laslo et al., 2006). The ectopic expression of TFs Maf-B, c-Maf, Egr1, IRF8, IRF4, and PU.1 in early progenitors can drive monocyte/macrophage and DC fates, and the given function of any factor depends on cooperating or antagonistic TFs that are expressed at each specific progenitor stage (Laslo et al., 2006). According to the current classification of DCs based on ontogeny, a discussion is being raised whether certain DC populations might only be considered as distinct subsets if their developmental pathway is controlled by specific TFs (Villar and Segura 2020). Plasmacytoid DCs develop from progenitors that express the E2-2, ZEB2, IRF8, and IRF4 TFs. Conventional DC1 arise from expression of IRF8 and BATF3, while cCD2 progenitors express ZEB2, IRF4 and Notch2/KLF4 TFs. Monocyte-derived DCs generation depend on the expression of the MAFB and KLF4 TFs (Collin and Bigley 2018; Guermonprez et al., 2019). The DC3 subset developmental pathway is still a matter of discussion, although recent studies have shed some light on this ongoing debate. Cultures of purified monocytes or monocyte-committed precursors with IRF8 ${ }^{\text {low }}$ expression were able to differentiate into DC3, while IRF8 ${ }^{\text {high }}$ progenitors gave rise to pDC and DC2 (Bourdely et al., 2020; Cytlak et al., 2020). Besides TFs, epigenetic modification and micro-RNAs have been described to be important determinants of lineage choice (O'Connell et al., 2007; O'Connell et al., 2008).

Altogether, the possibility of generating various terminally differentiated subsets of myeloid cells in vitro with cytokine and growth factor cocktails can be harnessed in immunotherapy approaches to develop novel cellular therapy products with optimized biological functions (Salmon et al., 2016).

\section{ROLE OF MONOCYTES, MACROPHAGES AND DENDRITIC CELLS IN CANCER The Tumor Microenvironment and its Chemoattractive millieu}

Macrophages are critical cells that participate of tissue homeostasis and regulation and may represent up to $50 \%$ of total immune cells that infiltrate solid tumors (Ramos et al., 2020). The great majority of TAMs are derived from blood monocytes due to the chemo attractive milieu from the tumor microenvironment, constituted by a large spectrum of soluble factors that includes M-CSF, CCL2, CCL3, CCL4, CCL5, CCL8, SDF1, VEGF, MIP-1, and MIF (Panni et al., 2013). The chemokine CCL2 was extensively studied and reported as one of the key factors inducing the accumulation of circulating monocytes within tumors (Kitamura et al., 2015; Cassetta and Pollard 2018). Due to the mostly suppressive activity of TAMs, a series of reports have proposed strategies to block the CCL2CCR2 axis aiming to avoid monocyte trafficking and accumulation into the tumor tissues. These studies revealed a significant impact on tumor growth and metastasis in pre-clinical settings (Qian et al., 2011; Macanas-Pirard et al., 2017; Nywening et al., 2018), but clinical trials failed to demonstrate similar efficacy (Fetterly et al., 2013; Pienta et al., 2013). Importantly, the restoration of the CCL2-CCR2 axis after blockage promotes new waves of monocyte recruitment and accumulation, inducing an acceleration of tumor growth on mice (Bonapace et al., 2014). In addition, no effect was noted on established tissue-resident macrophages in the tumor microenvironment after CCL2-CCR2 blockage (Zhu et al., 2017). Other molecules have been identified as promoting monocyte recruitment to tumor sites. The inhibition of CCL5-CCR5 interaction has been shown to have an impact on tumor growth and metastasis (Cambien et al., 2011; Ban et al., 2017). In fact, some studies have described CCL5 as a critical chemokine present in the tumor microenvironment that is able to promote the recruitment of DC to the tumor mass (Böttcher et al., 2018; Cueto et al., 2021). Once accumulated in the tissue, intratumoral DCs will, in turn, produce important levels of CXCL9 and CXCL10, critical chemokines that attract $\mathrm{T}$ cells within tumors (Spranger et al., 2017). This sequence of events may generate the stimulation of anti-tumor $\mathrm{T}$ cell responses and tumor control.

Targeting CXCR4, a receptor for CXCL12 molecule, has also been demonstrated to have an impact on monocyte recruitment in a colorectal tumor mouse model (Jung et al., 2017). More recently, two studies highlighted new signaling pathways able to induce monocyte/macrophage attraction and accumulation on tumors. Zhang and others showed that IFN- $\gamma$ affects CXCL8CXCR2 signaling and consequently reduced TAM trafficking within the tumor microenvironment (Zhang M. et al., 2020, 8). Takahashi et al. used in vitro assays to reveal the role of soluble-VCAM-1 molecule produced by pancreatic cancer cells in the chemo attraction of murine macrophages (Takahashi et al., 2020). Thus, a mixture of soluble factors may drive the migration of myeloid immune cells into the tumor microenvironment. The effective manipulation of the chemo attractive signals along with proper macrophage differentiation may promote the infiltration and accumulation of subpopulations of these cells capable of controlling the tumor.

\section{Monocytes}

Human monocytes represent around $10 \%$ of mononuclear cells in peripheral blood. For decades, many authors have used flow cytometry to further describe these cells into three major subsets 
with distinct proportions: classical monocytes $\mathrm{CD} 14^{\text {high }} \mathrm{CD} 16^{\text {neg }}$ (around $90 \%$ of total monocytes), intermediate monocytes $\mathrm{CD} 144^{\text {high }} \mathrm{CD} 16+$ (around $2 \%$ of total monocytes) and inflammatory monocytes $\mathrm{CD} 14^{\text {low }} \mathrm{CD} 16^{\text {high }}$ (around $8 \%$ of total monocytes) (Passlick et al., 1989; Ziegler-Heitbrock et al., 2010; Wong et al., 2012). Microarray mRNA analysis of FACSsorted monocytes revealed unique transcriptional gene profiles for each of these subsets (Wong et al., 2011). Among newly described markers, authors revealed, both at mRNA and at protein levels, that classical monocytes express higher levels of CD1d, CD99, CD9 and CD36; intermediate monocytes showed higher levels of CLEC10A and GFRa2; and inflammatory monocytes showed elevated expression of CD294, P2RX1, and SIGLEC10. Additional studies using pseudo-time scRNAseq analysis have confirmed that both non-classical monocytes subsets may originate from classical monocytes, in mice and humans (Mildner et al., 2017; Villani et al., 2017). Of note, the CD163 scavenger receptor, which has been extensively used to describe macrophages subsets (Ruffell and Coussens 2015; Ramos et al., 2020), is also expressed by monocytes and newly described DC subsets (Villani et al., 2017) and is significantly more expressed in both classical and intermediate monocytes, in comparison to inflammatory monocytes. More recently, singlecell approaches have re-oriented the description of monocyte subsets by revealing new markers and functional features of these cells. Two new markers, CD88 and CD89, were described as specifically expressed by human classical monocytes, discriminating these cells from other immune cell subsets (Dutertre et al., 2019; Bourdely et al., 2020). These new findings are of great interest, considering that the characterization of monocytes in tissues is still challenging, since many of their surface markers are shared with macrophages (e.g., CD14, CD68, and CD163).

Hematopoietic stem cells give rise to progenitors that will progressively generate monocyte-committed progenitors and, subsequently, monocytes. Importantly, elevated counts of blood monocytes were described in cancer patients and tumor-bearing mice (Cortez-Retamozo et al., 2012; Sanford et al., 2013; Trovato et al., 2019), where increased numbers of blood monocytes were associated to worse prognoses (Lee, 2012; Shigeta et al., 2016; Hayashi et al., 2017; Feng et al., 2018). This phenomenon is further supported by the elevated serum levels of CCL2, a critical cytokine for monocyte mobilization from bone marrow (Monti et al., 2003; Dehqanzada et al., 2007; Sanford et al., 2013). Coherently, additional factors were found increased in cancer patients' serum, including the classical growth factors: G-CSF, GM-CSF, and M-CSF (Scholl et al., 1996; Wu et al., 2014; Ribechini and Hutchinson 2017). Notably, M-CSF is critical during monocyte development, promoting survival and proliferation of myeloid progenitors towards monocytic cell lineages (Rieger et al., 2009). Moreover, blood monocytes under high concentrations of M-CSF may acquire an antiinflammatory profile, giving rise to potential suppressive mature macrophages (Menetrier-Caux et al., 1998; Jaguin et al., 2013; Ramos et al., 2020).

There are emerging data indicating that tumor-derived factors can affect monocyte differentiation remotely, altering bone marrow progenitors. A series of studies have uncovered an altered transcriptomic profile of circulating monocytes in both cancer patients (Chittezhath et al., 2014; Cassetta et al., 2019; Kiss et al., 2020; Ramos et al., 2020) and mouse tumor models (Torroella-Kouri et al., 2013; Stone et al., 2014) when compared to tumor-free individuals. One important consequence of this phenomenon is the biased differentiation programming found in patients' monocytes when compared to healthy donors, which gives rise to dysfunctional DC and macrophages (Ramos et al., 2012; Ramos et al., 2020), thus impacting adaptive anti-tumoral responses.

Due to their elevated degree of plasticity and sensitivity, monocytes can rapidly migrate and respond to inflammation in tissues. However, tumor-derived factors can also influence their process of differentiation by modulating their phenotype, differentiation and functions at tumor sites and systemically. Harnessing the great plasticity of monocytes and the precise definition of their differentiation pathways, it would be possible to recruit specifically functional cells, representing a great gain for the development of new therapies for cancer.

\section{Macrophages}

The function and phenotype of macrophages in the tumor microenvironment have been extensively described in the last decades (Ruffell and Coussens 2015). Most of the reports have associated the features of macrophages to an oversimplified bipolar model M1 (pro-inflammatory) $\mathrm{x}$ M2 (antiinflammatory) (Lacey et al., 2012; Jaguin et al., 2013). Proinflammatory M1-macrophages have been mostly associated to anti-tumoral responses, while M2-macrophages have shown proangiogenic and immunosuppressive capabilities (Pollard 2004). Based on this model, many studies have used M1 or M2-like markers to describe TAMs in distinct human tumor types. Most of the markers used included CD68, CD14, CD163, and CD206 (Steidl et al., 2010; Ruffell and Coussens 2015). CD68 and CD14 molecules are expressed by monocytes, macrophages and some DC subsets, regardless of their functional status. CD163 and CD206 markers currently correspond to an M2 immunosuppressive-like macrophages status, and are associated to poor patient prognosis for several solid and hematologic tumors, such as: breast (Medrek et al., 2012; Ramos et al., 2020), ovarian (Reinartz et al., 2014), pancreatic (Ino et al., 2013) and acute myeloid leukemia (Yang et al., 2018; Guo et al., 2021). In the recent years, with new technologies using large-scale single-cell approaches, the bipolar model of macrophage differentiation-M1 versus M2-macrophages-has been gradually replaced by a multidimensional landscape (Chevrier et al., 2017; Lavin et al., 2017; Azizi et al., 2018). Three new markers have emerged from recent studies using single-cell approaches redefining macrophage features on tumors: APOE (Apolipoprotein E), TREM2 (Triggering receptor expressed on myeloid cells 2) and FOLR2 (Folate receptor 2). APOE has been associated to a new panmacrophage marker, distinguishing these cells from blood monocytes (Lavin et al., 2017; Azizi et al., 2018). TREM2 was described as expressed on suppressive monocyte-derived macrophages that are accumulated on tumor sites 
(Katzenelenbogen et al., 2020; Molgora et al., 2020; Ardighieri et al., 2021). FOLR2 molecule is expressed on tissue-resident macrophages in a variety of tissues and was also found on stromal areas from human tumors (Sharma et al., 2020; Ramos et al., 2021).

Considering that macrophages are one of the most frequent immune infiltrating cells in solid tumors, a crescent number of reports have described anti-tumor strategies that target the immunosuppressive functions of TAMs (Liu and Wang 2020). These new "omics-studies" have uncovered distinct subsets of TAM and tissue-resident macrophages presenting a complex functional programming that offer new targets for molecular targeting and new perspectives for clinical interventions.

\section{Dendritic Cells}

Dendritic cells constitute a very heterogenous group of innate cells with specialized functions that are distributed in a wide variety of tissues. DC subsets are conserved across diverse human tumors and tissues (Gerhard et al., 2021). In contrast to other APCs, such as macrophages, B cells and monocytes, DC have a unique ability to migrate, transport and present tumor-antigens to naïve T cell in the lymphoid organs (Mildner and Jung 2014; Ruhland et al., 2020), being critical for the initiation of adaptive immune responses. A great range of tumors are devoid of DC infiltration (Broz et al., 2014), and it may explain the failure of anti-tumor $\mathrm{T}$ cell immunity in tumor control (Spranger et al., 2017).

Studies focused on DC biology in cancer have associated the presence of these cells with good patient outcome for distinct tumor types (Malietzis et al., 2015; Truxova et al., 2018; Melaiu et al., 2020). Not only the presence of DCs but their activation status and tissue spatial localization have highlighted the functional impact of these cells in patients. Ruffel and collaborators (Ruffell et al., 2012) have shown a decrease in frequency of tumor-infiltrating DCs in tumor areas when compared to normal adjacent tissues. Besides that, tumorinfiltrating DCs were described as dysfunctional and immature (Bell et al., 1999; Gervais et al., 2005; Dieu-Nosjean et al., 2008), and may participate in the tumor angiogenesis (Fainaru et al., 2008). In fact, DCs were also described as immature in tumor bed, in contrast to activated DCs found in tumor periphery (Treilleux et al., 2004; Baleeiro et al., 2008). A study by Goc and collaborators (Goc et al., 2014) correlated a lower risk of death in lung cancer patients with the presence of mature DCs and Th1like lymphocytes in peritumoral tertiary lymphoid structures (TLS). Many studies have explored the tumor-induced mechanisms responsible for the blockage of DC maturation and antigen presentation for $\mathrm{T}$ cells. Thomachot and others (Thomachot et al., 2004) showed that products derived from human breast carcinoma cell lines were able to block the in vitro maturation of DC derived from CD34+ progenitors. The accumulation of some metabolites such as fatty acid and lactic acid also impair the antigen processing and presentation as well as the production of pro-inflammatory cytokines by DC (Herber et al., 2010; Cao et al., 2014; Caronni et al., 2018). In addition, a variety of cytokines were reported as critical for dampening DC functionality. The vascular endothelial growth factor (VEGF) is highly expressed in the tumor microenvironment from distinct tumor types and inhibit the activity of FMS-like tyrosine kinase 3 ligand (FLT3L), a critical factor for DC development and maturation (Gabrilovich et al., 1996). IL-6 and IL-10 are known to play a critical role in the blockage of DC functions by promoting STAT3 activation, which may impede IL-12 production and promote IL-10 amplification (Diao et al., 2011; Tang et al., 2015). Farren and others (Farren et al., 2014) suggested that tumor-derived factors sustained STAT3 upregulation on myeloid cells progenitors avoiding the activation of ERK and NF-kB signaling, which may limit the monocyte capacity to be differentiated into DCs. Furthermore, TGF- $\beta$ present in the tumor microenvironment has been reported as critical to suppress DC maturation and inhibit their production of pro-inflammatory cytokines such as IL-12 and TNF- $\alpha$, hampering the activation of $\mathrm{T}$ cells (Belladonna et al., 2008; Flavell et al., 2010). Importantly, tumor factors may also affect myeloid APCs at circulation, since defective subpopulations of DCs were described in the blood of cancer patients (Satthaporn et al., 2004).

Recent reports using transgenic mice models and single-cell approaches have further detailed the intrinsic features of the distinct DC subsets in the oncology field. Both mouse and human $\mathrm{CDC1}$ were described as highly efficient for cross-presentation in the tumor context by stimulating $\mathrm{CD} 8+\mathrm{T}$ cells responses (Jongbloed et al., 2010; Wculek et al., 2019). Additional studies have described that type I interferon may enhance anti-tumor properties of $\mathrm{cDC1}$ cross-presentation and $\mathrm{CD} 8+\mathrm{T}$ cell stimulation (Diamond et al., 2011; Fuertes et al., 2011). The CDC2 subset constitute the most heterogenous population of conventional DCs presenting a wide diversity of phenotypes (Villani et al., 2017; Dutertre et al., 2019). These cells can produce a large spectrum of cytokines and are involved in the induction of diverse $\mathrm{CD} 4+\mathrm{T}$ helper subsets in both inflammatory and cancer contexts (Binnewies et al., 2019; Bosteels et al., 2020). The recently described DC3 is still under deep characterization. A study by Bourdely and others (Bourdely et al., 2020) have described the DC3 subset as effective for the priming of $\mathrm{CD} 8+\mathrm{CD} 103+$ tissue-resident memory $\mathrm{T}$ cells via the production of TGF-beta. In agreement, presence of DC3 are also associated to the accumulation of $\mathrm{CD} 8+\mathrm{T}$ tissue-resident memory cells in human breast cancer tissues. Dutertre and collaborators (Dutertre et al., 2019) also reported that DC3 are capable to expand $\mathrm{CD} 4+\mathrm{T}$ helper cells in vitro. Of note, $\mathrm{CD} 14+\mathrm{CD} 163+$ DC3 subset were strong inducers of CD4+IL17A+ Th17-likecells when compared to cDC2 subtype, suggesting their role in inflammatory responses.

The plasmacytoid DC subset has been extensively characterized in the tumor field. These cells were associated to a poor patients' prognosis in distinct types of cancer (Wculek et al., 2020). In fact, various reports have described a tolerogenic profile of tumorinfiltrating pDCs. Breast cancer infiltrating pDCs have shown an impaired capability to secrete IFN- $\alpha$ (Sisirak et al., 2012), which may be partially explained by the higher concentrations of TGF- $\beta$ and TNF- $\alpha$ found in the tumor microenvironment (Sisirak et al., 2013). Similarly, the dysfunctional pDCs profiling was described for other tumor types including ovarian (Labidi-Galy et al., 2011) 
and melanoma (Camisaschi et al., 2014). Other studies also uncovered the $\mathrm{pDC}$ role in the induction of suppressive CD4+ regulatory $\mathrm{T}$ cells in breast cancer patients, suggesting the mechanisms that explain their pro-tumorigenic profile (Faget et al., 2012; Sisirak et al., 2012).

Another critical DC subset described in many inflammatory conditions, including cancer, is the monocyte-derived DC. These cells can be found in the tissues from both mice and humans and emerge via the recruitment of CCR2+ monocytes from the blood (Schlitzer et al., 2015). In vivo, is still challenging to exactly define Mo-DCs phenotype and function due to their high plasticity and its profiling that overlaps with other DC subsets and macrophages (Collin and Bigley 2018). Many reports have described strategies for the manipulation of Mo-DCs due to the possibility of Mo-DC in vitro differentiation from blood monocytes (Sallusto and Lanzavecchia 1994) or CD34+ progenitors (Caux et al., 1996). It has allowed researchers to develop clinical protocols using Mo-DC based-vaccines to treat distinct diseases, including cancer (Barbuto et al., 2004; Neves et al., 2005). Mo-DCs plasticity can be also explored by treating monocytes with soluble factors, cytokines, TLR$\mathrm{L}$ and other compounds to drive their cellular functions towards the stimulation of a variety of $\mathrm{T}$ helper responses and/or CD8+ $\mathrm{T}$ cell activation (Harris 2011; Goudot et al., 2017). In vivo, Mo-DC has been associated to an anti-tumor function. Kuhn and collaborators (Kuhn et al., 2015) reported that the blockage of Mo-DC recruitment and differentiation in tumor sites impede the stimulation of antitumor immunity in mice models. In addition, Mo-DCs isolated from cancer patients are capable to cross-present tumor antigens and activate cytotoxic CD8+ T cells ex vivo (Tang-Huau et al., 2018).

Altogether, DCs critically participate in the initiation and expansion of anti-tumor adaptive immune responses with specialized functions and intrinsic roles for each subset. Despite all the uncertainty, however, DC continues as a central piece in tumor immunotherapy. From one side, the effectiveness of other immunotherapeutic modalities highlights the immune system's effector mechanisms potential in cancer therapy and DCs remain the best-known cells to initiate the immune responses that would recruit such mechanisms.

Another fact that should be considered when looking at DC in the context of immunotherapy is, from one side, the heterogeneity and plasticity of the immune response and, from the other, our still incomplete knowledge of its role in each disease. Although improving the scenario is still uncertain. However, the use of a cell, itself heterogeneous and plastic, and that is hardly constrained by our manipulations, leaves the door open to "unexpected" results, which might become those that actually point to the "right" way to achieve success. The comprehensive use of these cells by exploring their skills and improving their clinical application alone or in combination with other therapies may represent a great gain for cancer patients' treatment.

\section{CHIMERIC ANTIGEN RECEPTOR ON T CELLS AND NATURAL KILLER CELLS}

The development of $\mathrm{T}$ cells expressing CAR date from the first studies performed in the 80 's by Gross and collaborators
(Gross et al., 1989). This strategy was further optimized in the subsequent years by the comprehension of the critical mechanisms for CAR-T cell activation, expansion and in vivo survival (Krause et al., 1998; Maher et al., 2002; Brentjens et al., 2003). The first trials using genetically engineered $\mathrm{T}$ cells highlighted its safety and its impact on cancer patients' survival (Morgan et al., 2006; Kochenderfer et al., 2010), paving the way for the subsequent clinical applications. Since 2017, the Food and Drug Administration department (FDA, United States) has approved five products of CAR-T for refractory non-Hodgkin B cell lymphoma, acute lymphocytic leukemia and multiple myeloma (Maude et al., 2018; Park et al., 2018; Munshi et al., 2021). Lately, clinical trials using CAR-T cells have been really encouraging with studies reporting residual disease-negative complete responses for about $70 \%$ of patients with distinct hematological malignancies (Ortíz-Maldonado et al., 2021). More recently, studies have also focused on the improvement of the manufacturing process of CAR-T cells by aiming to diminish the time for production and costs, while ameliorating the quality and the life-spam of the cells in vivo. The creation of the 4 th generation (Chmielewski and Abken 2020) and bispecific CAR-T cells (Shah et al., 2020; Fousek et al., 2021) are examples of such improvements to be applied in the clinics.

Another recent strategy was the manufacture of NK cells expressing CAR. Many advantages were considered in the use of these cells to treat malignances, including: its intrinsic ability to eliminate cells with down regulated HLA expression, its application in allogenic scenarios and a lower potential of toxicity, which will reduce side-effects and costs with patients' conditioning (Moretta et al., 2011; Simonetta et al., 2017; Xie et al., 2020; Albinger et al., 2021). Pre-clinical reports have demonstrated that CAR-NKs generated from both peripheral blood and umbilical cord blood have effective capabilities to eliminate CD19+ target tumor cells in vitro (Herrera et al., 2019). In the clinical settings, trials using cord blood-derived CAR-NK for patients with B-cell malignancies showed very enthusiastic results, by reporting clinical responses in around $70 \%$ of treated individuals and CAR-NK persistence at the periphery for around 1 year (Liu et al., 2020).

Despite great success of CAR-T and CAR-NK treatment for hematological cancers, first clinical trials using CAR-T cells for solid tumors have reported disappointing results (Kershaw et al., 2006; Lamers et al., 2011; Thistlethwaite et al., 2017). Most clinical trials using CAR-NK for solid tumors are still ongoing and no conclusive results were presented so far. Many authors have extensively discussed the possible limitations for the success of CAR-T and CAR-NK in solid tumors (Hanahan and Coussens 2012; Li et al., 2018; Marofi et al., 2021). Main cited reasons include but are not limited to: the high mutational burden generating a diversity of tumor antigens, the dense extracellular matrix that may promote $\mathrm{T}$ cell exclusion, the absence of chemo-attractive factors for $\mathrm{T}$ cells, the limited in vivo persistence of CAR-T cells and the immunosuppressive microenvironment. 


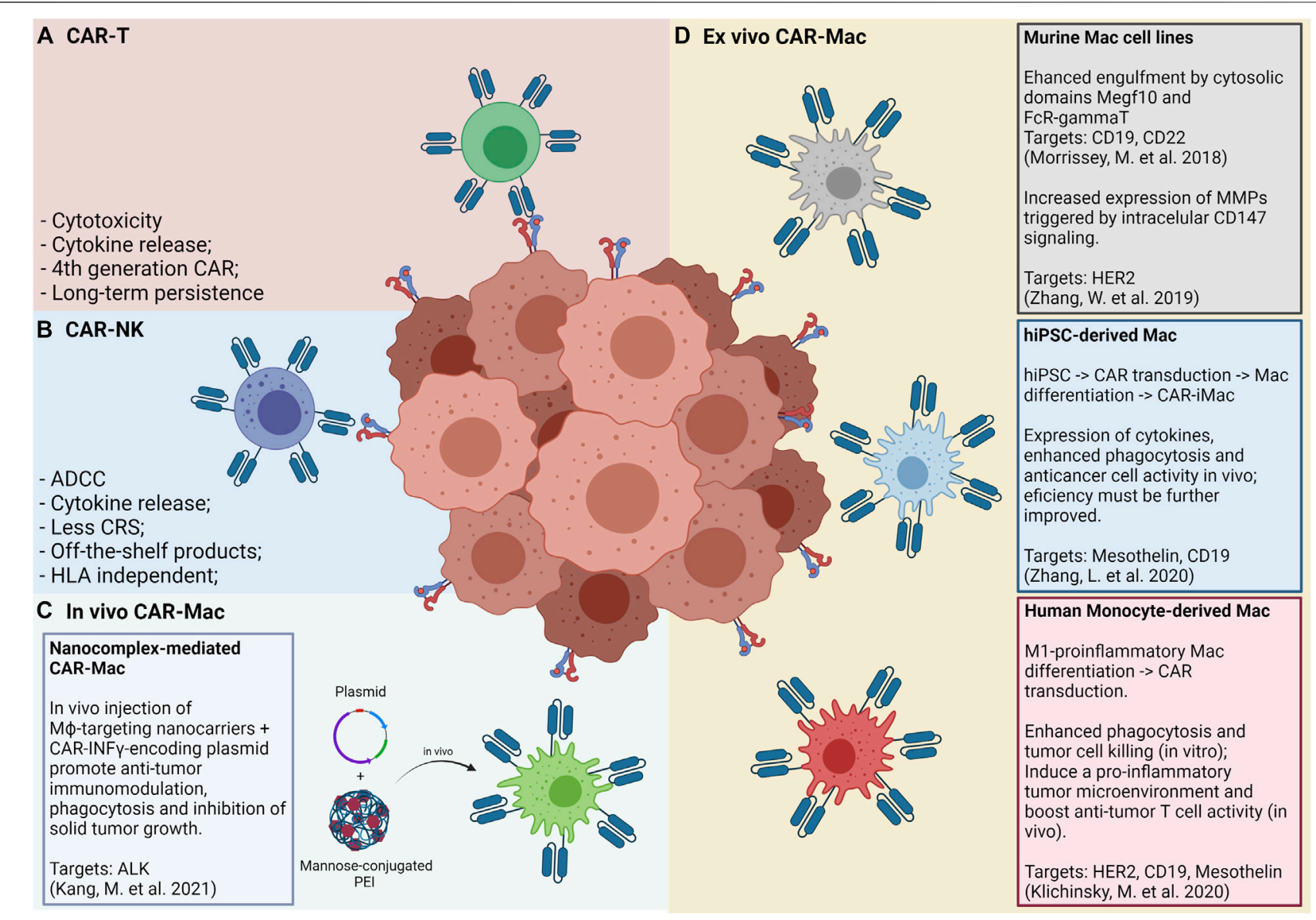

FIGURE 2|Panels (A) and (B) show the "classic" CAR-T and CAR-NK approaches, respectively, and its main features and advantages. Panel (C) shows an in vivo approach for CAR-Mac production, in which a nanocomplex composed of mannose-conjugated PEl and DNA plasmids is intratumorally or intraperitonially administered and internalized by local macrophages. Panel (D) shows the approaches so far tested for generating and applying CAR-Mac cells against solid tumors (Morrissey et al., 2018; Zhang et al., 2019; Klichinsky et al., 2020; Zhang L. et al., 2020). Both murine and human macrophages were reprogrammed to target at least four tumor markers (CD19, CD22, HER2, and Mesothelin). Human macrophages were obtained from peripheral blood monocytes and from iPS cells.

\section{CHIMERIC ANTIGEN RECEPTOR ON MYELOID IMMUNE CELLS}

The low efficacy of CAR-T cell therapies for solid tumors may be, probably, explained by the inability of these cells to effectively infiltrate the tumor mass. Among the main reasons for this failure are the lack of classical T-attractive chemokines (e.g., CXCL9 and CXCL10), the dense tumor microenvironment matrix and the higher tumor-antigen heterogeneity, as compared to hematologic tumors. To overcome these difficulties, recent studies have suggested the use of CAR-engineered monocytes/macrophages for the elimination of solid tumors. Still, few reports have described CAR-Mac functionalities, but this emerging topic has called the attention of the scientific community. We summarize below the key works recently published using CAR-Mac technologies highlighting their particularities (Figure 2).

The study by Morrissey and collaborators (2018) (Morrissey et al., 2018) used murine CAR-Mac constructs strategies to enhance the phagocytosis of cancer cells. The authors' strategy consists in an extracellular single-chain antibody variable fragment $(\mathrm{ScFv})$ specific for $\mathrm{CD} 19$ or $\mathrm{CD} 22$ with the $\mathrm{CD} 8$ transmembrane domain linked to a cytoplasmatic domain able to promote macrophage phagocytosis. By screening a library of intracellular domains of engulfment receptors, the authors selected the cytosolic domains from Megf10 and FcR-gamma, achieving a robust engulfment of antigen-coated synthetic particles. Macrophages expressing anti-CD19 or anti-CD22 CARs linked with the cytosolic domain Megf10 showed superior abilities of phagocytosis of synthetic beads with up to $20 \mu \mathrm{m}$ of size when compared to CAR-GFP controls. Authors further demonstrated that the synapse of CAR-Mac cell-bead interaction induced stimulation via phosphotyrosine expression at comparative levels of $\mathrm{CD} 3 \zeta$ signaling. Authors next tested the phagocytic capabilities of J774A.1 CAR-Mac expressing Megf10 and $\mathrm{FcR} \gamma$ intracellular domains in co-culture with human Raji $B$ cell lines, cells that express CD19 endogenously. Elegant images showed that CAR-Mac with both intracellular domains presented a significant higher capability to promote trogocytosis or to engulf tumor cells when compared to control CAR-Mac GFP+. This 
effect was further improved when the authors engineered CARMac to increase the PI3K employment by fusing the CD19 cytoplasmatic domain, which is able to recruit the p85 subunit of PI3K. Altogether, this study provides an attractive engineered strategy to increase engulfment and elimination of tumor cells by CAR-Mac.

Another interesting study reported by Zhang and others (2019) (Zhang et al., 2019) described a murine anti-HER2 CAR-Mac Raw264.7 engineered with an intracellular signaling domain of CD147 (CAR-147-Mac), able to trigger the expression of matrix metalloproteinase (MMPs) after antigen recognition. This strategy aims to remodel the tumor microenvironment extracellular matrix, facilitating the infiltration of immune cells or drugs. Authors showed that CAR-147-Mac were able to produce significant high levels of mRNA for distinct MMPs upon HER2 antigen binding in co-cultures with 4T1 cell lines during 24 and $48 \mathrm{~h}$. A more pronounced expression of $M M P 3$, $M M P 9, M M P 10$, and $M M P 13$ was noted when compared to cocultures between $4 \mathrm{~T} 1$ cell lines lacking HER2 antigen expression. For in vivo assays, CAR-147-Mac were found in liver and tumors of mice even after 7 days of intravenous infusion. No differences were noted in total body weight of HER2+ 4T1 tumor-bearing mice injected with both CAR-147-Mac or control CAR-Mac, but significant reduction of the weight of the spleen and tumor mass was noted in animals that received CAR-147-Mac. The infusion of CAR-147-Mac significantly inhibited HER2+ 4T1 tumor growth in mice along with an up-regulation of the anti-tumor cytokines such as IL-12 and IFN-gamma, thus suggesting that this strategy involves both local modulation and systemic anti-tumor responses. In addition, CAR-147-Mac treatment promoted an increase in T-cell infiltration and a reduction of GR1+ myeloid cells into tumors. Added, no differences were found in the infiltration of DCs, NKs, and TAMs as well as in markers of activation for T cells (PD-1, CD44, CD62L, and CD107a) when comparing tumor-bearing mice that received CAR-147-Mac or control CAR-Mac. In agreement, authors used balb/c nude mice model to demonstrate that no effect in tumor control was noted after CAR-147-Mac infusion. By showing IHC images from tumor sections authors reported a significant reduction in tumor collagen deposition in mice treated by CAR-147-Mac. Using a human in vitro $3 \mathrm{D}$ spheroid system by co-culturing THP CAR-147-Mac with HER2+ MDA-MB-453 tumor cell line authors showed an increased mRNA expression of various MMPs allowing the infiltration and accumulation of T cells. In conclusion, this study provided an interesting approach using engineered macrophages able to modify the extracellular matrix, allowing $\mathrm{T}$ cell infiltration in the tumor mass.

More recently, two additional studies reported strategies for CAR-Mac manufacturing using human cells as primary resources. Zhang and collaborators (Zhang L. et al., 2020) focused on undifferentiated stem cells by developing a threestep procedure: I) reprogramming human PBMCs towards an induced pluripotent stem cell (iPSCs) using non-integrating episomal vectors; II) engineering CAR expression on IPSCs by lentiviral transduction; III) promoting macrophage differentiation from CAR-iPSCs using a cocktail of growth factors and cytokines including bFGF, VEGF, SCF, IGF-1, IL-
3, M-CSF, and GM-CSF to obtain a final cell product of CAR induced macrophages (CAR-iMac). Authors firstly characterized and validated CAR-iMac phenotype at both transcriptional and protein levels. By flow cytometry iCAR-Mac closely resembled to primarily differentiated macrophages by showing the expression of typical proteins, such as CD11b, CD14, CD163, and CD68. At the transcriptional level CAR-iMac displayed a distinct programing from those undifferentiated IPS and clustered with primary differentiated macrophages. In addition, CAR-iMac present enrichment for genes related to GO pathways ofinnate immunity, antigen processing and presentation and positive regulation of cytokine production while expressing high levels of characteristic macrophage genes such asAIF1, CSFR1, and SPI1. Authors also implied scRNA-seq analysis and found that CAR-iMac cells clustered with macrophages already described in public datasets. Subsequently, authors aimed to validate functional features of iCAR-Mac against two antigens, CD19 and mesothelin. Anti-CD19 CAR-iMac co-cultured with CD19+ K562 cells expressed higher levels of TNF, IL1A, IL1B, and $I L-6$ and displayed enrichment on pathways related to antigen process and presentation and positive regulation of cytokine production when compared to control CD19- K562 cells. Authors also showed an increased phagocytosis of anti-CD19 CAR-iMac when K562 target cells expressed CD19. Similar results were obtained for in vitro assays using Meso+ OVCAR3 cells lines. For in vivo assays, NSG mice were injected with luciferase-expressing Meso+ HO8910 cell lines intraperitoneally, prior to anti-meso CAR-iMac infusion. Data showed a significant reduction in bioluminescent tumor cells when compared to PBS-treated mice at days 4,11 , and 14 post-treatment. Considering that pluripotent stem cells have a great expansion potential it could be maintained as an unlimited source. Thus, the platform for iPSC-derived engineered CAR-Mac emerges as a very promising approach to be further explored for a variety of malignancies and tumor antigens.

An elegant study by Klichinsky and others (Klichinsky et al., 2020) reported the engineering of CAR-Mac from human monocyte-derived macrophages applying the classical M1-like in vitro protocol based on GM-CSF treatment. Moreover, the authors established a new protocol for primary macrophage transduction with high reproducibility (validated in more than 10 distinct monocyte donors) and efficiency ( $>75 \%$ of CARpositive cells) by using the chimeric adenoviral vector Ad5f35. CAR-Mac manufactured with Ad5f35 adenovirus were able to efficiently phagocyte tumor cells from both hematological and solid tumor lines as well as control tumor growth in xenograft mouse models when administered via intravenous or intraperitoneal routes. Interestingly, CAR-Mac transfected with Ad5f35 showed superior phagocytic capacity than control M1like macrophages and presented a stable pro-inflammatory phenotype in the tumor microenvironment. CAR-Mac were also found infiltrating distinct organs from tumor bearingmice and persisted for up to 62 days in tumor-free animals. Surprisingly, the authors also reported efficient crosspresentation promoted by CAR-Mac transfected with Ad5f35, since in co-cultures with CAR-Mac pre-incubated with NYESO1+ tumor cell lines in an HLA-A201+ restricted 
context, an increase in NYESO1+CD8+CD69+ activated T lymphocytes and an up-regulation of IFN-gamma secretion was detected. In addition, CAR-Mac were able to efficiently recruit both resting and activated $\mathrm{T}$ cells in chemotaxis assays and to induce activation of immature DCs via soluble factors. Importantly, this study by Klichinsky and others (Klichinsky et al., 2020) paved the way for the first phase-I clinical trial using CAR-Mac launched in 2020 for a variety of HER2-overexpressing solid tumors (NCT04660929). In this study, the authors estimate the recruitment of patients with no available curative treatment options that will be separated into two treatment groups. One group will undergo intra subject dose escalation of IV administrations of up to 500 million cells on D+0, up to 1.5 billion cells on $\mathrm{D}+3$, and up to 3 billion cells on $\mathrm{D}+5$. The other group will receive a single dose of up to 5 billion cells on $\mathrm{D}+0$. As primary endpoints, the investigators will evaluate the safety and tolerability of the infused product by estimating the frequency and severity of adverse events (i.e., CRS) in the trial subjects during a 14 months follow-up period. The feasibility of manufacturing anti-HER2 CAR-Mac will also be assessed by describing the percentage of products that pass the release criteria. The Overall Response Rate (ORR), as well as the Progression Free Survival (PFS) of subjects that receive at least one dose of the product will be assessed as secondary endpoints within a time frame of 24 months.

More recently, Kang and collaborators (Kang et al., 2021) have described an in vivo approach for CAR-Mac reprograming using mannose-conjugated polyethylenimine (MPEI) nanocomplex as a gene delivery of plasmids for anti-ALK (anaplastic lymphoma kinase) CAR and IFN-gamma. Based on the fact that TAMs with anti-inflammatory properties may overexpress the mannose receptor (CD206), authors took advantage of this system to target macrophages in situ. They added in the plasmid construction the IFN- $\gamma$ gene, a classical known cytokine able to stimulate a pro-inflammatory phenotype (Ramos et al., 2020). Both ALK-CAR and IFN- $\gamma$ genes were cloned using the non-viral transposon system of piggyBac, for stable and persistent CAR expression. Using this systems authors proposed to target ALK tumor-antigen as well as to reprogram TAMs to acquire proinflammatory properties inducing adaptive immune $\mathrm{T}$ cell responses. Authors firstly validated the manufacturing of $\mathrm{MPEI} / \mathrm{pCAR}-\mathrm{IFN}-\gamma$ nanocomplexes indicating homogenous sizes and a great stability in serum for up to 7 days. Also, no cytotoxicity was noted in treated-bone marrow derived macrophages (BMDM), whereas CAR and IFN-gamma expression were validated in in vitro treated M2-BMDM. Of note, the efficiency of transfection was about $14 \%$ in M2-BMDM treated cells with a 20 -fold increasing in IFN-gamma expression. In terms of functional in vitro assays, authors reported an increase of phagocytosis capability of M2-BMDM MPEI/pCAR-IFN- $\gamma$ treated cells for distinct ratios of BMDM: ALK+ target Neuro2a tumor cell. In addition, M2-BMDM presented a shift of phenotype towards a M1-like profile once treated by MPEI/ IFN- $\gamma$ or MPEI/pCAR-IFN- $\gamma$ by showing a significantly downregulation of CD163, CD206, IL-10, and arginase-1 concomitantly with an up-regulation of CD80, CD86, and TNF-alpha. Subsequently, authors tested the in vivo effects of
MPEI/pCAR-IFN- $\gamma$ and variations of this construction in tumor growth and tumor microenvironment modulation. Using a Neuro-2a syngeneic tumor-bearing mice model, authors reported a significant control of tumor growth in animals receiving both $\mathrm{MPEI} / \mathrm{pCAR}$ or $\mathrm{MPEI} / \mathrm{IFN}-\gamma$, but this antitumoral effect was further increased under intratumoral infusion of the MPEI/pCAR-IFN- $\gamma$ full construct. By analyzing the tumor microenvironment composition after MPEI/pCARIFN- $\gamma$ treatment, authors found a significant increase in CD8+ $\mathrm{T}$ cell infiltration and INOS expression along with a strongly reduced expression of Arginase-1, TGF-beta, and IL10, indicating local immune modulation effects. Alternatively, by injecting $\mathrm{MPEI} / \mathrm{pCAR}-\mathrm{IFN}-\gamma$ intraperitoneally in tumor-bearing mice authors showed presence of CAR+ immune cells in liver, kidney and tumor mass as well as a significant effect on tumor control, even considering it less pronounced than intratumoral infusion. In conclusion, the transfection efficiency observed in this study was lower than that of lentiviral transduction and should be further improved. Importantly, in vivo infusion of MPEI/pCAR-IFN- $\gamma$ nanocomplex allows the transfection of a variety of immune cells, including DCs and T lymphocytes, possibly amplifying the anti-tumoral effects. Thus, this nanocomplex strategy may overcome the high costs, the exhaustive process for CAR-Mac manufacturing and avoid the concerns of the use of viral vectors representing an important new avenue for future strategies.

\section{LIMITATIONS OF CAR-MYELOID CELLS}

We have summarized in Table $\mathbf{1}$ the main differences among CAR-T, CAR-NK, and CAR-myeloid cells by highlighting the process for manufacturing of these cells and their potential applications. Two important obstacles of using myeloid cells in CAR-based therapies are the inability of primary macrophages and DCs to expand in vitro and the difficulty in delivering exogenous genetic material (Keller et al., 2018). Viral and nonviral delivery systems were tested in macrophages and DCs in the past decades and both presented limitations. Professional phagocytes present a powerful immune response against viral DNA making it difficult to efficiently deliver a transgene through viral vectors. On the other hand, the application of physical transfection such as nucleoporation or nucleofection did not elicit important immune responses but caused important changes in gene expression profile and functional status of macrophages and DCs (Harizaj et al., 2021). As a matter of comparison, the main steps of CAR-T cell production involve the reprogramming and expansion of $\mathrm{T}$ cells in order to obtain a high number of CAR+ cells before infusion. New studies have described the use of artificial APCs to stimulate $\mathrm{T}$ cells. The distinct approaches include cell lines modified to provide antigen-presentation and co-stimulation (Couture et al., 2019; Schmidts et al., 2020) and synthetic complexes of mesoporous silica microrods loaded with soluble mitogenic compounds and T-cell ligands (Zhang D. K. Y. et al., 2020). Recent studies have also described strategies to stimulate NK cells based on cytokine cocktails, generating a memory-like phenotype (Pahl et al., 2018). These cells present 
TABLE 1 | Comparison of key manufacturing steps for CAR-based cellular products (CAR-T, CAR-NK, and CAR-Myeloid cells) and its specific advantages and disadvantages. PEI, Polyethylenimine; GM-CSF, Granulocyte-macrophage colony-stimulating factor; M-CSF, Macrophage colony-stimulating factor.

\begin{tabular}{|c|c|c|c|}
\hline & CAR-T cells & CAR-NK cells & $\begin{array}{c}\text { CAR-myeloid cells (CAR-Mac, } \\
\text { CAR-DC) }\end{array}$ \\
\hline $\begin{array}{l}\text { 1. Cell type and } \\
\text { selection }\end{array}$ & Positive selection of CD3+ and/or CD4+ or CD8+ cells & $\begin{array}{l}\text { Positive selection of CD56+ } \\
\text { cells }\end{array}$ & Positive or negative selection of CD14+ cells \\
\hline \multirow[t]{2}{*}{$\begin{array}{l}\text { 2. Activation/ } \\
\text { differentiation }\end{array}$} & Beads/antibodies anti-CD3/CD28 & $\begin{array}{l}\text { Beads/antibodies anti- } \\
\text { CD335/CD2 }\end{array}$ & $\begin{array}{l}\text { Culture with GM-CSF, M-CSF, TNF-alpha, IFN- } \\
\text { gamma }\end{array}$ \\
\hline & Artificial APC cell lines & $\begin{array}{l}\text { Culture with IL-2, IL-15 and/or } \\
\mathrm{IL}-21\end{array}$ & TLR-Ligands \\
\hline \multicolumn{4}{|l|}{ 3. Gene delivery } \\
\hline \multirow{2}{*}{$\begin{array}{l}\text { 3.1 CAR viral } \\
\text { delivery }\end{array}$} & Retroviral vector & Retroviral vector & Adenoviral vector \\
\hline & Lentiviral vector & Lentiviral vector & Lentiviral vector \\
\hline \multirow[t]{5}{*}{$\begin{array}{l}\text { 3.2 Non-Viral CAR } \\
\text { delivery }\end{array}$} & Nucleoporation & Nucleoporation & $\begin{array}{l}\text { Nanocomplex (Mannose-associated PEI + DNA } \\
\text { plasmid) }\end{array}$ \\
\hline & Liposomes & Liposomes & Expression systems \\
\hline & Expression systems & Expression systems & PiggyBac \\
\hline & Sleeping Beauty; PiggyBac; mRNA & $\begin{array}{l}\text { Sleeping Beauty; PiggyBac; } \\
\text { mRNA }\end{array}$ & \\
\hline & Nanoplasmids & Nanoplasmids & \\
\hline 4. Expansion & Culture with IL-2, IL-7, IL-15 and/or IL-21 & $\begin{array}{l}\text { K562 feeder cells expressing } \\
\text { membrane bound IL-21 } \\
\text { Culture with IL-12 and IL-15 } \\
\text { Memory-like phenotype: IL-12, } \\
\text { IL-15, and IL-18 }\end{array}$ & $\begin{array}{l}\text { Primary human macrophages cannot be expanded } \\
\text { ex vivo } \\
\text { THP-1 cell line spontaneously expands in vitro and } \\
\text { can be differentiated when cultured with PMA. }\end{array}$ \\
\hline \multicolumn{4}{|l|}{ 5. Final Product } \\
\hline 5.1 Lifespan & Long-term persistence after tumor remission & Mid-term lifespan in vivo & $\begin{array}{l}\text { Short-term lifespan of myeloid cells in vivo (no } \\
\text { available data for CAR-Myeloid) }\end{array}$ \\
\hline \multirow[t]{4}{*}{ 5.2 Advantages } & Efficient selection, activation and easy handling & $\begin{array}{l}\text { Applicable in allogenic } \\
\text { scenarios }\end{array}$ & Applicable in allogenic scenarios \\
\hline & & Low toxicity & Low toxicity in animal models \\
\hline & & $\begin{array}{l}\text { Can be obtained from multiple } \\
\text { sources }\end{array}$ & Potential application in solid tumors \\
\hline & & & $\begin{array}{l}\text { CAR-DCs may present a migratory potential to } \\
\text { lymphoid organs }\end{array}$ \\
\hline \multirow[t]{2}{*}{$\begin{array}{l}5.3 \\
\text { Disadvantages }\end{array}$} & $\begin{array}{l}\text { Long-term cultures and/or high doses of IL-2 can induce } \\
\text { terminally differentiated/exhausted T cells or biased } \\
\text { expansion of regulatory CD } 4+T \text { cells }\end{array}$ & $\begin{array}{l}\text { Few cells are obtained after } \\
\text { selection }\end{array}$ & Laborious transfection procedures \\
\hline & $\begin{array}{l}\text { Cytokine release syndrome (CRS) and/or Immune effector } \\
\text { cell associated neurotoxicity syndrome (ICANS) may occur } \\
\text { Long-term "on-target, off-tumor" effects (ex.: B cell aplasia } \\
\text { when targeting CD19) }\end{array}$ & $\begin{array}{l}\text { Laborious expansion and } \\
\text { genetic modification }\end{array}$ & $\begin{array}{l}\text { Difficult genetic reprogramming due to the } \\
\text { recognition of foreign genetic material } \\
\text { No results from clinical trials so far }\end{array}$ \\
\hline
\end{tabular}

a long-lived profiling by expanding and producing IFN-gamma some weeks post-infusion. Considering that macrophages and DCs do not have the same potential of expansion as compared to T or NK cells, the number of CAR-Mac or CAR-DCs available for infusion would be significantly lower than in CAR-T or CAR-NK applications, which may limit their use in large tumors or in strategies using multiple doses.

Besides, the relatively short lifespan of CAR-Mac compared to CAR-T cells and CAR-NKs is a topic of concern. As discussed above, first studies are encouraging, but additional pre-clinical tests are needed to evaluate the functional status, the persistence of CAR-Mac in vivo, as well as the variation of cell number needed for infusion. To assure that CAR-Mac will reach the tumor mass in the shortest possible time after infusion, diverse routes of injection should be further explored in tumors of distinct origins since tissue arquiteture may vary considerably. So far, few targets have been tested in the use of pre-clinical CAR-Mac and clinical translation of CAR-myeloid cells and the future of its application relies on the overcome of technical obstacles.

\section{CONCLUDING REMARKS}

Myeloid immune cells engineered to express CAR opened a new pathway to treat cancer that, apparently, bypasses the limitations of CAR-T or CAR-NK cells. Additional advantages of myeloid cells should be further explored and combined with CAR- 
engineering. In addition, the lack of response to a checkpoint inhibitor would be better explained by the absence of a response to be released from its inhibitors and, thus, DC and macrophages associated to CAR expression would be ideal candidates to add to checkpoint inhibition, a combination that is already under investigation (Wilgenhof et al., 2016). We highlighted below some key points to be considered in the use of CARexpressing myeloid cells for solid cancers:

I) Migratory ability: monocytes and DC subtypes have great migratory skills towards a variety of inflamed and/or lymphoid tissues. The manipulation of these features needs to be further enhanced to drive these cells into specific tissues or tumor mass in a more controlled way.

II) Plasticity potential: numerous protocols of differentiation and activation may allow a better phenotypical and functional fine-tuning adjustment of monocytes, macrophages and DCs to be adapted for distinct tumor contexts and tissues. The combined use of growth factors, cytokines/chemokines, TLR-L and drugs may generate a more effective and functional manufactured CARmyeloid cell.

III) Phagocytic skills: macrophages and DCs have unique abilities of phagocytosis and clearance for a variety of particles. The manufacturing of cells with an improved engulfment ability to eliminate tumor cells may represent a great gain in the control of malignances.

IV) Tissue remodeling: monocytes/macrophages could be reprogrammed to release a series of enzymes, cathepsins, MMPs and other modulatory factors not only to remodel the tumor microenvironment matrix but also to attract, allow the infiltration and stimulate $\mathrm{T}$ cells.

\section{REFERENCES}

Ajami, B., Bennett, J. L., Krieger, C., Tetzlaff, W., and Rossi, F. M. V. (2007). Local Self-Renewal Can Sustain CNS Microglia Maintenance and Function throughout Adult Life. Nat. Neurosci. 10 (12), 1538-1543. doi:10.1038/nn2014

Albinger, N., Hartmann, J., and Ullrich, E. (2021). Current Status and Perspective of CAR-T and CAR-NK Cell Therapy Trials in Germany. Gene Ther. 28 (9), 513-527. doi:10.1038/s41434-021-00246-w

Anderson, N. R., Minutolo, N. G., Gill, S., and Klichinsky, M. (2021). MacrophageBased Approaches for Cancer Immunotherapy. Cancer Res. 81 (5), 1201-1208. doi:10.1158/0008-5472.CAN-20-2990

Ardighieri, L., Missale, F., Bugatti, M., Gatta, L. B., Pezzali, I., Monti, M., et al. (2021). Infiltration by CXCL10 Secreting Macrophages Is Associated with Antitumor Immunity and Response to Therapy in Ovarian Cancer Subtypes. Front. Immunol. 12 (junho), 690201. doi:10.3389/ fimmu.2021.690201

Auffray, C., Sieweke, M. H., and Geissmann, F. (2009). Blood Monocytes: Development, Heterogeneity, and Relationship with Dendritic Cells. Annu. Rev. Immunol. 27 (1), 669-692. doi:10.1146/annurev.immunol.021908.132557

Azizi, E., Carr, A. J., Plitas, G., Cornish, A. E., Konopacki, C., Prabhakaran, S., et al. (2018). Single-Cell Map of Diverse Immune Phenotypes in the Breast Tumor Microenvironment. Cell 174 (5), 1293-1308.e36. doi:10.1016/ j.cell.2018.05.060

Bachem, A., Güttler, S., Hartung, E., Ebstein, F., Schaefer, M., Tannert, A., et al. (2010). Superior Antigen Cross-Presentation and XCR1 Expression Define Human CD11c+CD141+ Cells as Homologues of Mouse CD8+ Dendritic Cells. J. Exp. Med. 207 (6), 1273-1281. doi:10.1084/jem.20100348
V) Stimulation of adaptive immunity: myeloid immune cells are capable of efficiently present tumor antigens, provide costimulatory signals and produce cytokines able to efficiently stimulate lymphocyte activation and expansion.

There is an emergent need to evaluate CAR-myeloid immune cells in distinct pre-clinical tumor types, considering intrinsic tissue-related factors, matrix architecture and cellular composition. Tumor growth and its intrinsic features deeply vary among models and, possibly, additional adjusts should be implemented in the manufacture of CAR-Mac. Importantly, the use of myeloid cells expressing CAR could be further combined with other clinical approaches able to disrupt the compact matrix of solid tumors and may represent a great gain for patients' outcome. These therapies include, but are not limited to, chemotherapy, radiotherapy, oncolytic virus and/or monoclonal agonistic antibodies.

\section{AUTHOR CONTRIBUTIONS}

$\mathrm{RR}$ and VR Conceptualization, writting and review of the article; TO, SC, PK, TB, ER, and JB writting, figure preparation and review of the article.

\section{ACKNOWLEDGMENTS}

RR, SC, TO, PK and VR are supported by CNPq \#442676/2020-4. JB is supported by CNPq: \# 308053/2017-6. Figures were created using Biorender.com.

Bakri, Y., Sarrazin, S., Mayer, U. P., Tillmanns, S., Nerlov, C., Boned, A., et al. (2005). Balance of MafB and PU.1 Specifies Alternative Macrophage or Dendritic Cell Fate. Blood 105 (7), 2707-2716. doi:10.1182/blood-2004-04-1448

Baleeiro, R. B., Anselmo, L. B., Soares, F. A., Pinto, C. A. L., Ramos, O., Gross, J. L., et al. (2008). High Frequency of Immature Dendritic Cells and Altered In Situ Production of Interleukin-4 and Tumor Necrosis Factor- $\alpha$ in Lung Cancer. Cancer Immunol. Immunother. 57 (9), 1335-1345. doi:10.1007/s00262-0080468-7

Ban, Y., Mai, J., Li, X., Mitchell-Flack, M., Zhang, T., Zhang, L., et al. (2017). Targeting Autocrine CCL5-CCR5 Axis Reprograms Immunosuppressive Myeloid Cells and Reinvigorates Antitumor Immunity. Cancer Res. 77 (11), 2857-2868. doi:10.1158/0008-5472.CAN-16-2913

Barbuto, J. A. M., Ensina, L. F. C., Neves, A. R., Bergami-Santos, P., Leite, K. R. M., Marques, R., et al. (2004). Dendritic Cell?Tumor Cell Hybrid Vaccination for Metastatic Cancer. Cancer Immunol. Immunother. 53 (12), 1111-1118. doi:10.1007/s00262-004-0551-7

Bell, D., Chomarat, P., Broyles, D., Netto, G., Harb, G. M., Lebecque, S., et al. (1999). In Breast Carcinoma Tissue, Immature Dendritic Cells Reside within the Tumor, whereas Mature Dendritic Cells Are Located in Peritumoral Areas. J. Exp. Med. 190 (10), 1417-1426. doi:10.1084/jem.190.10.1417

Belladonna, M. L., Volpi, C., Bianchi, R., Vacca, C., Orabona, C., Pallotta, M. T., et al. (2008). Cutting Edge: Autocrine TGF- $\beta$ Sustains Default Tolerogenesis by Ido-Competent Dendritic Cells. J. Immunol. 181 (8), 5194-5198. doi:10.4049/ jimmunol.181.8.5194

Binnewies, M., Mujal, A. M., Pollack, J. L., Combes, A. J., Hardison, E. A., Barry, K. C., et al. (2019). Unleashing Type-2 Dendritic Cells to Drive Protective Antitumor CD4+ T Cell Immunity. Cell 177 (3), 556-571.e16. doi:10.1016/ j.cell.2019.02.005 
Blériot, C., Chakarov, S., and Ginhoux, F. (2020). Determinants of Resident Tissue Macrophage Identity and Function. Immunity 52 (6), 957-970. doi:10.1016/ j.immuni.2020.05.014

Bonapace, L., Coissieux, M.-M., Wyckoff, J., Mertz, K. D., Varga, Z., Junt, T., et al. (2014). Cessation of CCL2 Inhibition Accelerates Breast Cancer Metastasis by Promoting Angiogenesis. Nature 515 (7525), 130-133. doi:10.1038/ nature 13862

Bosteels, C., Neyt, K., Vanheerswynghels, M., van Helden, M. J., Sichien, D., Debeuf, N., et al. (2020). Inflammatory Type 2 CDCs Acquire Features of $\mathrm{CDC1s}$ and Macrophages to Orchestrate Immunity to Respiratory Virus Infection. Immunity 52 (6), 1039-1056.e9. doi:10.1016/j.immuni.2020.04.005

Böttcher, J. P., Bonavita, E., Chakravarty, P., Blees, H., Cabeza-Cabrerizo, M., Sammicheli, S., et al. (2018). NK Cells Stimulate Recruitment of CDC1 into the Tumor Microenvironment Promoting Cancer Immune Control. Cell 172 (5), 1022-1037.e14. doi:10.1016/j.cell.2018.01.004

Bourdely, P., Anselmi, G., Vaivode, K., RamosRamos, R. N., Missolo-Koussou, Y., Hidalgo, S., et al. (2020). Transcriptional and Functional Analysis of CD1c+ Human Dendritic Cells Identifies a CD163+ Subset Priming CD8+CD103+ T Cells. Immunity 53 (2), 335-352.e8. doi:10.1016/j.immuni.2020.06.002

Brentjens, R. J., Latouche, J.-B., Santos, E., Marti, F., Gong, M. C., Lyddane, C., et al. (2003). Eradication of Systemic B-Cell Tumors by Genetically Targeted Human T Lymphocytes Co-stimulated by CD80 and Interleukin-15. Nat. Med. 9 (3), 279-286. doi:10.1038/nm827

Broz, M. L., Binnewies, M., Boldajipour, B., Nelson, A. E., Pollack, J. L., Erle, D. J., et al. (2014). Dissecting the Tumor Myeloid Compartment Reveals Rare Activating Antigen-Presenting Cells Critical for T Cell Immunity. Cancer Cell 26 (5), 638-652. doi:10.1016/j.ccell.2014.09.007

Cambien, B., Richard-Fiardo, P., Karimdjee, B. F., Martini, V., Ferrua, B., Pitard, B., et al. (2011). CCL5 Neutralization Restricts Cancer Growth and Potentiates the Targeting of PDGFR $\beta$ in Colorectal Carcinoma. PLoS ONE 6 (12), e28842. doi:10.1371/journal.pone.0028842

Camisaschi, C., De Filippo, A., Beretta, V., Vergani, B., Villa, A., Vergani, E., et al. (2014). Alternative Activation of Human Plasmacytoid DCs In Vitro and in Melanoma Lesions: Involvement of LAG-3. J. Invest. Dermatol. 134 (7), 1893-1902. doi:10.1038/jid.2014.29

Cao, W., Ramakrishnan, R., Tuyrin, V. A., Veglia, F., Condamine, T., Amoscato, A., et al. (2014). Oxidized Lipids Block Antigen Cross-Presentation by Dendritic Cells in Cancer. J.I. 192 (6), 2920-2931. doi:10.4049/jimmunol.1302801

Caronni, N., Simoncello, F., Stafetta, F., Guarnaccia, C., Ruiz-Moreno, J. S., Opitz, B., et al. (2018). Downregulation of Membrane Trafficking Proteins and Lactate Conditioning Determine Loss of Dendritic Cell Function in Lung Cancer. Cancer Res. 78 (7), 1685-1699. doi:10.1158/0008-5472.CAN-17-1307

Cassetta, L., Fragkogianni, S., Sims, A. H., Swierczak, A., Forrester, L. M., Zhang, H., et al. (2019). Human Tumor-Associated Macrophage and Monocyte Transcriptional Landscapes Reveal Cancer-specific Reprogramming, Biomarkers, and Therapeutic Targets. Cancer Cell 35 (4), 588-602.e10. doi:10.1016/j.ccell.2019.02.009

Cassetta, L., and Pollard, J. W. (2018). Targeting Macrophages: Therapeutic Approaches in Cancer. Nat. Rev. Drug Discov. 17 (12), 887-904. doi:10.1038/nrd.2018.169

Caux, C., Vanbervliet, B., Massacrier, C., Dezutter-Dambuyant, C., de Saint-Vis, B., JacquetYoneda, C., et al. (1996). CD34+ Hematopoietic Progenitors from Human Cord Blood Differentiate along Two Independent Dendritic Cell Pathways in Response to GM-CSF+TNF Alpha. J. Exp. Med. 184 (2), 695-706. doi:10.1084/jem.184.2.695

Chaib, M., Chauhan, S. C., and Makowski, L. (2020). Friend or Foe? Recent Strategies to Target Myeloid Cells in Cancer. Front. Cel Dev. Biol. 8 (maio), 351. doi:10.3389/fcell.2020.00351

Chen, Y., Yu, Z., Tan, X., Jiang, H., Xu, Z., Fang, Y., et al. (2021). CAR-macrophage: A New Immunotherapy Candidate against Solid Tumors. Biomed. Pharmacother. 139 (julho), 111605. doi:10.1016/j.biopha.2021.111605

Chevrier, S., Levine, J. H., Zanotelli, V. R. T., Silina, K., Schulz, D., Bacac, M., et al. (2017). An Immune Atlas of Clear Cell Renal Cell Carcinoma. Cell 169 (4), 736-749.e18. doi:10.1016/j.cell.2017.04.016

Chittezhath, M., Dhillon, M. K., Lim, J. Y., Laoui, D., Shalova, I. N., Teo, Y. L., et al. (2014). Molecular Profiling Reveals a Tumor-Promoting Phenotype of Monocytes and Macrophages in Human Cancer Progression. Immunity 41 (5), 815-829. doi:10.1016/j.immuni.2014.09.014
Chmielewski, M., and Abken, H. (2020). TRUCKS, the Fourth-generation CAR T Cells: Current Developments and Clinical Translation. Adv. Cel Gene Ther 3 (3), 84. doi:10.1002/acg2.84

Coillard, A., and Segura, E. (2019). In Vivo Differentiation of Human Monocytes. Front. Immunol. 10 (agosto), 1907. doi:10.3389/fimmu.2019.01907

Collin, M., and Bigley, V. (2018). Human Dendritic Cell Subsets: An Update. Immunology 154 (1), 3-20. doi:10.1111/imm.12888

Cortez-Retamozo, V., Etzrodt, M., Newton, A., Rauch, P. J., Chudnovskiy, A., Berger, C., et al. (2012). Origins of Tumor-Associated Macrophages and Neutrophils. Proc. Natl. Acad. Sci. 109 (7), 2491-2496. doi:10.1073/ pnas.1113744109

Couture, A., Garnier, A., Docagne, F., Boyer, O., Vivien, D., Le-Mauff, B., et al. (2019). HLA-class II Artificial Antigen Presenting Cells in CD4+ T Cell-Based Immunotherapy. Front. Immunol. 10 (maio), 1081. doi:10.3389/ fimmu.2019.01081

Cueto, F. J., del Fresno, C., Brandi, P., Combes, A. J., Hernández-García, E., Sánchez-Paulete, A. R., et al. (2021). DNGR-1 Limits Flt3L-Mediated Antitumor Immunity by Restraining Tumor-Infiltrating Type I Conventional Dendritic Cells. J. Immunother. Cancer 9 (5), e002054. doi:10.1136/jitc-2020-002054

Cytlak, U., Resteu, A., Pagan, S., Green, K., Milne, P., McDonald, S., et al. (2020). Differential IRF8 Transcription Factor Requirement Defines Two Pathways of Dendritic Cell Development in Humans. Immunity 53 (2), 353-370.e8. doi:10.1016/j.immuni.2020.07.003

Dehqanzada, Z., Storrer, C. E., Hueman, M. T., Foley, R. J., Harris, K. A., Jama, Y. H., et al. (2007). Assessing Serum Cytokine Profiles in Breast Cancer Patients Receiving a HER2/Neu Vaccine Using Luminex Technology. Oncol. Rep. 17 (3), 687-694. doi:10.3892/or.17.3.687

Demaria, O., Cornen, S., Daëron, M., Morel, Y., Medzhitov, R., and Vivier, E. (2019). Harnessing Innate Immunity in Cancer Therapy. Nature 574 (7776), 45-56. doi:10.1038/s41586-019-1593-5

Diamond, M. S., Kinder, M., Matsushita, H., Mashayekhi, M., Dunn, G. P., Archambault, J. M., et al. (20112003). Type I Interferon Is Selectively Required by Dendritic Cells for Immune Rejection of Tumors. J. Exp. Med. 208 (10), 1989-2003. doi:10.1084/jem.20101158

Diao, J., Zhao, J., Winter, E., and Cattral, M. S. (2011). Tumors Suppress In Situ Proliferation of Cytotoxic T Cells by Promoting Differentiation of Gr-1+ Conventional Dendritic Cells through IL-6. J.I. 186 (9), 5058-5067. doi:10.4049/jimmunol.1004125

Dieu-Nosjean, M.-C., Antoine, M., Danel, C., Heudes, D., Wislez, M., Poulot, V., et al. (2008). Long-Term Survival for Patients with Non-small-cell Lung Cancer with Intratumoral Lymphoid Structures. J. Clin. Oncol. 26 (27), 4410-4417. doi:10.1200/JCO.2007.15.0284

Dokka, S., Toledo, D., Shi, X., Ye, J., and Rojanasakul, Y. (2000). High-Efficiency Gene Transfection of Macrophages by Lipoplexes. Int. J. Pharm. 206 (1-2), 97-104. doi:10.1016/S0378-5173(00)00531-7

Doulatov, S., Notta, F., Eppert, K., Nguyen, L. T., OhashiOhashi, P. S., and Dick, J. E. (2010). Revised Map of the Human Progenitor Hierarchy Shows the Origin of Macrophages and Dendritic Cells in Early Lymphoid Development. Nat. Immunol. 11 (7), 585-593. doi:10.1038/ni.1889

Dutertre, C.-A., Becht, E., Irac, S. E., Khalilnezhad, A., Narang, V., Khalilnezhad, S., et al. (2019). Single-Cell Analysis of Human Mononuclear Phagocytes Reveals Subset-Defining Markers and Identifies Circulating Inflammatory Dendritic Cells. Immunity 51 (3), 573-589.e8. doi:10.1016/j.immuni.2019.08.008

Engblom, C., Pfirschke, C., and Pittet, M. J. (2016). The Role of Myeloid Cells in Cancer Therapies. Nat. Rev. Cancer 16 (7), 447-462. doi:10.1038/nrc.2016.54

Epelman, S., Lavine, K. J., and Randolph, G. J. (2014). Origin and Functions of Tissue Macrophages. Immunity 41 (1), 21-35. doi:10.1016/ j.immuni.2014.06.013

Faget, J., Bendriss-Vermare, N., Gobert, M., Durand, I., Olive, D., Biota, C., et al. (2012). ICOS-ligand Expression on Plasmacytoid Dendritic Cells Supports Breast Cancer Progression by Promoting the Accumulation of Immunosuppressive CD4+ T Cells. Cancer Res. 72 (23), 6130-6141. doi:10.1158/0008-5472.CAN-12-2409

Fainaru, O., Adini, A., Benny, O., Adini, I., Short, S., Bazinet, L., et al. (2008). Dendritic Cells Support Angiogenesis and Promote Lesion Growth in a Murine Model of Endometriosis. FASEB j. 22 (2), 522-529. doi:10.1096/fj.07-9034com 
Farren, M. R., Carlson, L. M., Netherby, C. S., Lindner, I., Abrams, L. P.-K., Gabrilovich, D. I., et al. (2014). Tumor-Induced STAT3 Signaling in Myeloid Cells Impairs Dendritic Cell Generation by Decreasing PKC $\beta I I$ Abundance. Sci. Signal. 7 (313), 4656. doi:10.1126/scisignal.2004656

Feng, F., Zheng, G., Wang, Q., Liu, S., Liu, Z., Xu, G., et al. (2018). Low Lymphocyte Count and High Monocyte Count Predicts Poor Prognosis of Gastric Cancer. BMC Gastroenterol. 18 (1), 148. doi:10.1186/s12876-018-0877-9

Fetterly, G. J., Aras, U., Meholick, P. D., Takimoto, C., Seetharam, S., McIntosh, T., et al. (2013). Utilizing Pharmacokinetics/pharmacodynamics Modeling to Simultaneously Examine Free CCL2, Total CCL2 and Carlumab (CNTO 888) Concentration Time Data. J. Clin. Pharmacol. 53 (10), 1020-1027. doi:10.1002/jcph.140

Flavell, R. A., Sanjabi, S., Wrzesinski, S. H., and Licona-Limón, P. (2010). The Polarization of Immune Cells in the Tumour Environment by TGF $\beta$. Nat. Rev. Immunol. 10 (8), 554-567. doi:10.1038/nri2808

Fousek, K., Watanabe, J., Joseph, S. K., George, A., An, X., Byrd, T. T., et al. (2021). CAR T-Cells that Target Acute B-Lineage Leukemia Irrespective of CD19 Expression. Leukemia 35 (1), 75-89. doi:10.1038/s41375-020-0792-2

Fuertes, M. B., Kacha, A. K., KlineWoo, J., Woo, S.-R., Kranz, D. M., Murphy, K. M., et al. (2011). Host Type I IFN Signals Are Required for Antitumor CD8+ T Cell Responses through CD8a+ Dendritic Cells. J. Exp. Med. 208 (10), 2005-2016. doi:10.1084/jem.20101159

Gabrilovich, D. I., Chen, H. L., Girgis, K. R., Cunningham, H. T., Girgis, K. R., Cunningham, H. T., et al. (1996). Production of Vascular Endothelial Growth Factor by Human Tumors Inhibits the Functional Maturation of Dendritic Cells. Nat. Med. 2 (10), 1096-1103. doi:10.1038/nm1096-1096

Gerhard, G. M., Bill, R., Messemaker, M., Klein, A. M., and Pittet, M. J. (2021). Tumor-Infiltrating Dendritic Cell States Are Conserved across Solid Human Cancers. J. Exp. Med. 218 (1), 264. doi:10.1084/jem.20200264

Gervais, A., Levêque, J., Bouet-Toussaint, F., Burtin, F., Lesimple, T., Sulpice, L., et al. (2005). Dendritic Cells Are Defective in Breast Cancer Patients: A Potential Role for Polyamine in This Immunodeficiency. Breast Cancer Res. 7 (3), 1. doi:10.1186/bcr1001

Ginhoux, F., and Jung, S. (2014). Monocytes and Macrophages: Developmental Pathways and Tissue Homeostasis. Nat. Rev. Immunol. 14 (6), 392-404. doi:10.1038/nri3671

Goc, J., Germain, C., Vo-Bourgais, T. K. D., Lupo, A., Klein, C., Knockaert, S., et al. (2014). Dendritic Cells in Tumor-Associated Tertiary Lymphoid Structures Signal a Th1 Cytotoxic Immune Contexture and License the Positive Prognostic Value of Infiltrating CD8+ T Cells. Cancer Res. 74 (3), 705-715. doi:10.1158/ 0008-5472.CAN-13-1342

Goudot, C., Coillard, A., Villani, A.-C., Gueguen, P., Cros, A., Sarkizova, S., et al. (2017). Aryl Hydrocarbon Receptor Controls Monocyte Differentiation into Dendritic Cells versus Macrophages. Immunity 47 (3), 582-596.e6. doi:10.1016/ j.immuni.2017.08.016

Gross, G., Waks, T., and Eshhar, Z. (1989). Expression of Immunoglobulin-T-Cell Receptor Chimeric Molecules as Functional Receptors with Antibody-type Specificity. Proc. Natl. Acad. Sci. 86 (24), 10024-10028. doi:10.1073/ pnas.86.24.10024

Guermonprez, P., Gerber-Ferder, Y., Vaivode, K., Bourdely, P., and Helft, J. (2019). Origin and Development of Classical Dendritic Cells. Int. Rev. Cel Mol. Biol. 349, 1-54. doi:10.1016/bs.ircmb.2019.08.002

Guilliams, M., Ginhoux, F., Jakubzick, C., Naik, S. H., Onai, N., Schraml, B. U., et al. (2014). Dendritic Cells, Monocytes and Macrophages: A Unified Nomenclature Based on Ontogeny. Nat. Rev. Immunol. 14 (8), 571-578. doi:10.1038/nri3712

Guo, R., Lü, M., Cao, F., Wu, G., Gao, F., Pang, H., et al. (2021). Single-Cell Map of Diverse Immune Phenotypes in the Acute Myeloid Leukemia Microenvironment. Biomark Res. 9 (1), 15. doi:10.1186/s40364-021-00265-0

Hanahan, D., and Coussens, L. M. (2012). Accessories to the Crime: Functions of Cells Recruited to the Tumor Microenvironment. Cancer Cell 21 (3), 309-322. doi:10.1016/j.ccr.2012.02.022

Harizaj, A., De Smedt, S. C., Lentacker, I., and Braeckmans, K. (2021). Physical Transfection Technologies for Macrophages and Dendritic Cells in Immunotherapy. Expert Opin. Drug Deliv. 18 (2), 229-247. doi:10.1080/ 17425247.2021.1828340

Harris, K. M. (2011). Monocytes Differentiated with GM-CSF and IL-15 Initiate Th17 and Th1 Responses that Are Contact-dependent and Mediated by IL- 15 . J. Leukoc. Biol. 90 (4), 727-734. doi:10.1189/jlb.0311132
Hayashi, T., Fujita, K., Nojima, S., Hayashi, Y., Nakano, K., Ishizuya, Y., et al. (2017). Peripheral Blood Monocyte Count Reflecting Tumor-Infiltrating Macrophages Is a Predictive Factor of Adverse Pathology in Radical Prostatectomy Specimens. Prostate 77 (14), 1383-1388. doi:10.1002/pros.23398

Helft, J., Anjos-Afonso, F., van der Veen, A. G., Chakravarty, P., Bonnet, D., Reis e Sousa, C., et al. (2017). Dendritic Cell Lineage Potential in Human Early Hematopoietic Progenitors. Cel Rep. 20 (3), 529-537. doi:10.1016/ j.celrep.2017.06.075

Herber, D. L., Cao, W., Nefedova, Y., Novitskiy, S. V., Nagaraj, S., Tyurin, V. A., et al. (2010). Lipid Accumulation and Dendritic Cell Dysfunction in Cancer. Nat. Med. 16 (8), 880-886. doi:10.1038/nm.2172

Herrera, L., Santos, S., Vesga, M. A., Anguita, J., Martin-Ruiz, I., Carrascosa, T., et al. (2019). Adult Peripheral Blood and Umbilical Cord Blood NK Cells Are Good Sources for Effective CAR Therapy against CD19 Positive Leukemic Cells. Sci. Rep. 9 (1), 18729. doi:10.1038/s41598-019-55239-y

Hoeffel, G., Chen, J., Lavin, Y., Low, D., Almeida, F. F., See, P., et al. (2015). C-Myb+ Erythro-Myeloid Progenitor-Derived Fetal Monocytes Give Rise to Adult Tissue-Resident Macrophages. Immunity 42 (4), 665-678. doi:10.1016/ j.immuni.2015.03.011

Hoeffel, G., and Ginhoux, F. (2015). Ontogeny of Tissue-Resident Macrophages. Front. Immunol. 6 (setembro), 486. doi:10.3389/fimmu.2015.00486

Ino, Y., Shimada, K., Yamazaki-Itoh, R., Shimada, K., Iwasaki, M., Kosuge, T., et al. (2013). Immune Cell Infiltration as an Indicator of the Immune Microenvironment of Pancreatic Cancer. Br. J. Cancer 108 (4), 914-923. doi:10.1038/bjc.2013.32

Jaguin, M., Houlbert, N., Fardel, O., and Lecureur, V. (2013). Polarization Profiles of Human M-CSF-Generated Macrophages and Comparison of M1-Markers in Classically Activated Macrophages from GM-CSF and M-CSF Origin. Cell Immunol. 281 (1), 51-61. doi:10.1016/j.cellimm.2013.01.010

Jongbloed, S. L., Kassianos, A. J., McDonald, K. J., Angel, C. G. J., Chen, C-J. J., Ju, X., et al. (2010). Human CD141+ (BDCA-3)+ Dendritic Cells (DCs) Represent a Unique Myeloid DC Subset that Cross-Presents Necrotic Cell Antigens. J. Exp. Med. 207 (6), 1247-1260. doi:10.1084/jem.20092140

Jung, K., Heishi, T., Incio, J., Huang, Y., Beech, E. Y., Pinter, M., et al. (2017). Targeting CXCR4-dependent Immunosuppressive Ly6Clow Monocytes Improves Antiangiogenic Therapy in Colorectal Cancer. Proc. Natl. Acad. Sci. USA 114 (39), 10455-10460. doi:10.1073/pnas.1710754114

Kang, M., Lee, S. H., Kwon, M., Byun, J., Kim, D., Kim, C., et al. (2021). Nanocomplex-Mediated In Vivo Programming to Chimeric Antigen Receptor-M1 Macrophages for Cancer Therapy. Adv. Mater. 33 (43), 2103258. doi:10.1002/adma.202103258

Katzenelenbogen, Y., Sheban, F., Yalin, A., Yofe, I., Svetlichnyy, D., Jaitin, D. A., et al. (2020). Coupled ScRNA-Seq and Intracellular Protein Activity Reveal an Immunosuppressive Role of TREM2 in Cancer. Cell 182 (4), 872-885.e19. doi:10.1016/j.cell.2020.06.032

Keller, A.-A., Maeß, M. B., Schnoor, M., Scheiding, B., and Lorkowski, S. (2018). "Transfecting Macrophages," in Methods in Molecular Biology (New York, NY: Springer New York), 187-195. doi:10.1007/978-1-4939-7837-3_18

Kershaw, M. H., Westwood, J. A., Parker, L. L., Wang, G., Eshhar, Z., Mavroukakis, S. A., et al. (2006). A Phase I Study on Adoptive Immunotherapy Using GeneModified T Cells for Ovarian Cancer. Clin. Cancer Res. 12 (20), 6106-6115. doi:10.1158/1078-0432.CCR-06-1183

Kiss, M., Caro, A. A., Raes, G., and Laoui, D. (2020). Systemic Reprogramming of Monocytes in Cancer. Front. Oncol. 10 (setembro), 1399. doi:10.3389/ fonc.2020.01399

Kitamura, T., Qian, B.-Z., Soong, D., Cassetta, L., Noy, R., Sugano, G., et al. (2015). CCL2-Induced Chemokine Cascade Promotes Breast Cancer Metastasis by Enhancing Retention of Metastasis-Associated Macrophages. J. Exp. Med. 212 (7), 1043-1059. doi:10.1084/jem.20141836

Klichinsky, M., Ruella, M., Shestova, O., Lu, X. M., Best, A., Zeeman, M., et al. (2020). Human Chimeric Antigen Receptor Macrophages for Cancer Immunotherapy. Nat. Biotechnol. 38 (8), 947-953. doi:10.1038/s41587-0200462-y

Kochenderfer, J. N., Wilson, W. H., Janik, J. E., Dudley, M. E., Stetler-Stevenson, M., Feldman, S. A., et al. (2010). Eradication of B-Lineage Cells and Regression of Lymphoma in a Patient Treated with Autologous T Cells Genetically Engineered to Recognize CD19. Blood 116 (20), 4099-4102. doi:10.1182/ blood-2010-04-281931 
Krause, A., Guo, H.-F., Latouche, J.-B., Tan, C., Cheung, N.-K. V., and Sadelain, M. E. M. (1998). Antigen-dependent CD28 Signaling Selectively Enhances Survival and Proliferation in Genetically Modified Activated Human Primary $\mathrm{T}$ Lymphocytes. J. Exp. Med. 188 (4), 619-626. doi:10.1084/jem.188.4.619

Kuhn, S., Yang, J., and Ronchese, F. (2015). Monocyte-Derived Dendritic Cells Are Essential for CD8+ T Cell Activation and Antitumor Responses after Local Immunotherapy. Front. Immunol. 6 (novembro), 584. doi:10.3389/ fimmu.2015.00584

Labidi-Galy, S. I., Sisirak, V., Meeus, P., Gobert, M., Treilleux, I., Bajard, A., et al. (2011). Quantitative and Functional Alterations of Plasmacytoid Dendritic Cells Contribute to Immune Tolerance in Ovarian Cancer. Cancer Res. 71 (16), 5423-5434. doi:10.1158/0008-5472.CAN-11-0367

Lacey, D. C., Achuthan, A., Fleetwood, A. J., Dinh, H., Roiniotis, J., Scholz, G. M., et al. (2012). Defining GM-CSF- and Macrophage-CSF-dependent Macrophage Responses by In Vitro Models. J.I. 188 (11), 5752-5765. doi:10.4049/ jimmunol.1103426

Ladányi, A., Kiss, J., Somlai, B., Gilde, K., Fejös, Z., Mohos, A., et al. (2007). Density of DC-LAMP+ Mature Dendritic Cells in Combination with Activated T Lymphocytes Infiltrating Primary Cutaneous Melanoma Is a Strong Independent Prognostic Factor. Cancer Immunol. Immunother. 56 (9), 1459-1469. doi:10.1007/s00262-007-0286-3

Lamers, C. H. J., Willemsen, R., van Elzakker, P., van Steenbergen-Langeveld, S., Broertjes, M., Oosterwijk-Wakka, J., et al. (2011). Immune Responses to Transgene and Retroviral Vector in Patients Treated with Ex Vivoengineered T Cells. Blood 117 (1), 72-82. doi:10.1182/blood-2010-07-294520

Laslo, P., Spooner, C. J., Warmflash, A., Lancki, D. W., Lee, H.-J., Sciammas, R., et al. (2006). Multilineage Transcriptional Priming and Determination of Alternate Hematopoietic Cell Fates. Cell 126 (4), 755-766. doi:10.1016/ j.cell.2006.06.052

Lavin, Y., Kobayashi, S., Leader, A., Amir, E.-A. D., Elefant, N., Bigenwald, C., et al. (2017). Innate Immune Landscape in Early Lung Adenocarcinoma by Paired Single-Cell Analyses. Cell 169 (4), 750-765.e17. doi:10.1016/j.cell.2017.04.014

Leal Rojas, I. M., Mok, W.-H., Pearson, F. E., Minoda, Y., Kenna, T. J., Barnard, R. T., et al. (2017). Human Blood CD1c+ Dendritic Cells Promote Th1 and Th17 Effector Function in Memory CD4+ T Cells. Front. Immunol. 8 (agosto), 971. doi:10.3389/fimmu.2017.00971

Lee, Y.-Y., Choi, C. H., Sung, C. O., Do, I.-G., Huh, S., Song, T., et al. (2012). Prognostic Value of Pre-treatment Circulating Monocyte Count in Patients with Cervical Cancer: Comparison with SCC-Ag Level. Gynecol. Oncol. 124 (1), 92-97. doi:10.1016/j.ygyno.2011.09.034

Li, J., Li, W., Huang, K., Zhang, Y., Kupfer, G., and Zhao, Q. (2018). Chimeric Antigen Receptor T Cell (CAR-T) Immunotherapy for Solid Tumors: Lessons Learned and Strategies for Moving Forward. J. Hematol. Oncol. 11 (1), 22. doi:10.1186/s13045-018-0568-6

Liu, E., Marin, D., Banerjee, P., Macapinlac, H. A., Thompson, P., Basar, R., et al. (2020). Use of CAR-Transduced Natural Killer Cells in CD19-Positive Lymphoid Tumors. N. Engl. J. Med. 382 (6), 545-553. doi:10.1056/ NEJMoa1910607

Liu, Y., and Wang, R. (2020). Immunotherapy Targeting Tumor-Associated Macrophages. Front. Med. 7 (novembro), 583708. doi:10.3389/ fmed.2020.583708

Macanas-Pirard, P., Quezada, T., Navarrete, L., Broekhuizen, R., Leisewitz, A., Nervi, B., et al. (2017). The CCL2/CCR2 Axis Affects Transmigration and Proliferation but Not Resistance to Chemotherapy of Acute Myeloid Leukemia Cells. PLOS ONE 12 (1), e0168888. doi:10.1371/journal.pone.0168888

Maher, J., Brentjens, R. J., Gunset, G., Rivière, I., and Sadelain, M. (2002). Human T-Lymphocyte Cytotoxicity and Proliferation Directed by a Single Chimeric TCR//CD28 Receptor. Nat. Biotechnol. 20 (1), 70-75. doi:10.1038/nbt0102-70

Malietzis, G., Lee, G. H., Jenkins, J. T., Bernardo, D., Moorghen, M., Knight, S. C., et al. (2015). Prognostic Value of the Tumour-Infiltrating Dendritic Cells in Colorectal Cancer: A Systematic Review. Cel Commun. Adhes. 22 (1), 9-14. doi:10.3109/15419061.2015.1036859

Marofi, F., Motavalli, R., Safonov, V. A., Thangavelu, L., Yumashev, A. V., Alexander, M., et al. (2021). CAR T Cells in Solid Tumors: Challenges and Opportunities. Stem Cel Res Ther 12 (1), 81. doi:10.1186/s13287-020-02128-1

Maude, S. L., Laetsch, T. W., Buechner, J., Rives, S., Boyer, M., Bittencourt, H., et al. (2018). Tisagenlecleucel in Children and Young Adults with B-Cell
Lymphoblastic Leukemia. N. Engl. J. Med. 378 (5), 439-448. doi:10.1056/ NEJMoa1709866

Medrek, C., Pontén, F., Jirström, K., and Leandersson, K. (2012). The Presence of Tumor Associated Macrophages in Tumor Stroma as a Prognostic Marker for Breast Cancer Patients. BMC Cancer 12 (1), 306. doi:10.1186/1471-2407-12-306

Melaiu, O., Chierici, M., Lucarini, V., Jurman, G., Conti, L. A., De Vito, R., et al. (2020). Cellular and Gene Signatures of Tumor-Infiltrating Dendritic Cells and Natural-Killer Cells Predict Prognosis of Neuroblastoma. Nat. Commun. 11 (1), 5992. doi:10.1038/s41467-020-19781-y

Menetrier-Caux, C., Montmain, G., Dieu, M. C., Bain, C., Favrot, M. C., Caux, C., et al. (1998). Inhibition of the Differentiation of Dendritic Cells from CD34+ Progenitors by Tumor Cells: Role of Interleukin- 6 and Macrophage ColonyStimulating Factor. Blood 92 (12), 4778-4791. doi:10.1182/blood.v92.12.4778

Merad, M., and Manz, M. G. (2009). Dendritic Cell Homeostasis. Blood 113 (15), 3418-3427. doi:10.1182/blood-2008-12-180646

Mildner, A., and Jung, S. (2014). Development and Function of Dendritic Cell Subsets. Immunity 40 (5), 642-656. doi:10.1016/j.immuni.2014.04.016

Mildner, A., Schönheit, J., Giladi, A., David, E., Lara-Astiaso, D., Lorenzo-Vivas, E., et al. (2017). Genomic Characterization of Murine Monocytes Reveals C/EBP $\beta$ Transcription Factor Dependence of Ly6C - Cells. Immunity 46 (5), 849-862.e7. doi:10.1016/j.immuni.2017.04.018

Molgora, M., Esaulova, E., Vermi, W., Hou, J., Chen, Y., Luo, J., et al. (2020). TREM2 Modulation Remodels the Tumor Myeloid Landscape Enhancing AntiPD-1 Immunotherapy. Cell 182 (4), 886-900.e17. doi:10.1016/j.cell.2020.07.013

Monti, P., Leone, B. E., Marchesi, F., Balzano, G., Zerbi, A., Scaltrini, F., et al. (2003). The CC Chemokine MCP-1/CCL2 in Pancreatic Cancer Progression: Regulation of Expression and Potential Mechanisms of Antimalignant Activity. Cancer Res. 63 (21), 7451-7461.

Moretta, L., Locatelli, F., Pende, D., Marcenaro, E., Mingari, M. C., and Moretta, A. (2011). Killer Ig-like Receptor-Mediated Control of Natural Killer Cell Alloreactivity in Haploidentical Hematopoietic Stem Cell Transplantation. Blood 117 (3), 764-771. doi:10.1182/blood-2010-08-264085

Morgan, R. A., Dudley, M. E., Hughes, M. S., Yang, J. C., Sherry, R. M., Royal, R. E., et al. (2006). Cancer Regression in Patients after Transfer of Genetically Engineered Lymphocytes. Science 314 (5796), 126-129. doi:10.1126/science.1129003

Morrissey, M. A., Williamson, A. P., Steinbach, A. M., Roberts, E. W., Kern, N., Headley, M. B., et al. (2018). Chimeric Antigen Receptors that Trigger Phagocytosis. ELife 7 (junho), e36688. doi:10.7554/eLife.36688

Munshi, N. C., Anderson, L. D., Shah, N., Madduri, D., Berdeja, J., Lonial, S., et al. (2021). Idecabtagene Vicleucel in Relapsed and Refractory Multiple Myeloma. N. Engl. J. Med. 384 (8), 705-716. doi:10.1056/NEJMoa2024850

Neophytou, C. M., Pierides, C., Christodoulou, M.-I., Costeas, P., Kyriakou, T.-C., and Papageorgis, P. (2020). The Role of Tumor-Associated Myeloid Cells in Modulating Cancer Therapy. Front. Oncol. 10 (junho), 899. doi:10.3389/ fonc. 2020.00899

Neves, A. R., Ensina, L. F. C., Leite, K. R. M., Buzaid, A. C., Câmara-Lopes, L. H., and Barbuto, J. A. M. (2005). Dendritic Cells Derived from Metastatic Cancer Patients Vaccinated with Allogeneic Dendritic Cell?Autologous Tumor Cell Hybrids Express More CD86 and Induce Higher Levels of Interferon-Gamma in Mixed Lymphocyte Reactions. Cancer Immunol. Immunother. 54 (1), 61-66. doi:10.1007/s00262-004-0550-8

Nywening, T. M., Belt, B. A., Cullinan, D. R., PanniPanni, R. Z., Han, B. J., Sanford, D. E., et al. (2018). Targeting Both Tumour-Associated CXCR2+ Neutrophils and CCR2+ Macrophages Disrupts Myeloid Recruitment and Improves Chemotherapeutic Responses in Pancreatic Ductal Adenocarcinoma. Gut 67 (6), 1112-1123. doi:10.1136/gutjnl-2017-313738

O’Connell, R. M., Rao, D. S., Chaudhuri, A. A., Boldin, M. P., Taganov, K. D., Nicoll, J., et al. (2008). Sustained Expression of MicroRNA-155 in Hematopoietic Stem Cells Causes a Myeloproliferative Disorder. J. Exp. Med. 205 (3), 585-594. doi:10.1084/jem.20072108

O'Connell, R. M., Taganov, K. D., Boldin, M. P., Cheng, G., and Baltimore, D. (2007). MicroRNA-155 Is Induced during the Macrophage Inflammatory Response. Proc. Natl. Acad. Sci. 104 (5), 1604-1609. doi:10.1073/ pnas.0610731104

Ortíz-Maldonado, V., Rives, S., Castellà, M., Alonso-Saladrigues, A., BenítezRibas, D., Caballero-Baños, M., et al. (2021). CART19-BE-01: A Multicenter Trial of ARI-0001 Cell Therapy in Patients with CD19+ 
Relapsed/Refractory Malignancies. Mol. Ther. 29 (2), 636-644. doi:10.1016/j.ymthe.2020.09.027

Pahl, J. H. W., Cerwenka, A., and Ni, J. (2018). Memory-Like NK Cells: Remembering a Previous Activation by Cytokines and NK Cell Receptors. Front. Immunol. 9 (novembro), 2796. doi:10.3389/fimmu.2018.02796

Panni, R. Z., Linehan, D. C., and DeNardo, D. G. (2013). Targeting TumorInfiltrating Macrophages to Combat Cancer. Immunotherapy 5 (10), 1075-1087. doi:10.2217/imt.13.102

Park, J. H., Rivière, I., Gonen, M., Wang, X., Sénéchal, B., Curran, K. J., et al. (2018). Long-Term Follow-Up of CD19 CAR Therapy in Acute Lymphoblastic Leukemia. N. Engl. J. Med. 378 (5), 449-459. doi:10.1056/NEJMoa1709919

Passlick, B., Flieger, D., and Ziegler-Heitbrock, H. (1989). Identification and Characterization of a Novel Monocyte Subpopulation in Human Peripheral Blood. Blood $74 \quad$ (7), 2527-2534. doi:10.1182/ blood.v74.7.2527.bloodjournal7472527

Pienta, K. J., Machiels, J.-P., Schrijvers, D., Alekseev, B., Shkolnik, M., Crabb, S. J., et al. (2013). Phase 2 Study of Carlumab (CNTO 888), a Human Monoclonal Antibody against CC-Chemokine Ligand 2 (CCL2), in Metastatic CastrationResistant Prostate Cancer. Invest. New Drugs 31 (3), 760-768. doi:10.1007/ s10637-012-9869-8

Pollard, J. W. (2004). Tumour-Educated Macrophages Promote Tumour Progression and Metastasis. Nat. Rev. Cancer 4 (1), 71-78. doi:10.1038/nrc1256

Qian, B.-Z., Li, J., Zhang, H., Kitamura, T., Zhang, J., Campion, L. R., et al. (2011). CCL2 Recruits Inflammatory Monocytes to Facilitate Breast-Tumour Metastasis. Nature 475 (7355), 222-225. doi:10.1038/nature10138

Ramos, R. N., Chin, L. S., dos Santos, A. P. S. A., Bergami-Santos, P. C., Laginha, F., and Barbuto, J. A. M. (2012). Monocyte-Derived Dendritic Cells from Breast Cancer Patients Are Biased to Induce CD4+CD25+Foxp3+ Regulatory T Cells. J. Leukoc. Biol. 92 (3), 673-682. doi:10.1189/jlb.0112048

Ramos, R. N., Missolo-Koussou, Y., Gerber-Ferder, Y., Bromley, C., Bugatti, M., Núñez, N. G., et al. (2021). Tissue-resident FOLR2+ Macrophages Associate with Tumor-Infiltrating CD8+ T Cells and with Increased Survival of Breast Cancer Patients. Preprint. Immunol. doi:10.1101/2021.04.12.439412

Ramos, R. N., Rodriguez, C., Hubert, M., Ardin, M., Treilleux, I., Ries, C. H., et al. (2020). CD163 + Tumor-associated Macrophage Accumulation in Breast Cancer Patients Reflects Both Local Differentiation Signals and Systemic Skewing of Monocytes. Clin. Transl Immunol. 9 (2), 1108. doi:10.1002/cti2.1108

Reinartz, S., Schumann, T., Finkernagel, F., Wortmann, A., Jansen, J. M., Meissner, W., et al. (2014). Mixed-polarization Phenotype of Ascites-associated Macrophages in Human Ovarian Carcinoma: Correlation of CD163 Expression, Cytokine Levels and Early Relapse. Int. J. Cancer 134 (1), 32-42. doi:10.1002/ijc.28335

Reizis, B., Bunin, A., Ghosh, H. S., LewisLewis, K. L., and Sisirak, V. (2011). Plasmacytoid Dendritic Cells: Recent Progress and Open Questions. Annu. Rev. Immunol. 29 (1), 163-183. doi:10.1146/annurev-immunol-031210-101345

Ribechini, E., Hutchinson, J. A., Hergovits, S., Heuer, M., Lucas, J., Schleicher, U., et al. (2017). Novel GM-CSF Signals via IFN-Tr/irf-1 and AKT/mTOR License Monocytes for Suppressor functionNovel GM-CSF Signals via IFN- $r$ r/irf- 1 and AKT/MTOR License Monocytes for Suppressor Function. Blood Adv. 1 (14), 947-960. doi:10.1182/bloodadvances.2017006858

Rieger, M. A., Hoppe, P. S., Smejkal, B. M., Eitelhuber, A. C., and Schroeder, T. (2009). Hematopoietic Cytokines Can Instruct Lineage Choice. Science 325 (5937), 217-218. doi:10.1126/science.1171461

Ruffell, B., Au, A., Rugo, H. S., Esserman, L. J., Hwang, E. S., and Coussens, L. M. (2012). Leukocyte Composition of Human Breast Cancer. Proc. Natl. Acad. Sci. 109 (8), 2796-2801. doi:10.1073/pnas.1104303108

Ruffell, B., and Coussens, L. M. (2015). Macrophages and Therapeutic Resistance in Cancer. Cancer Cell 27 (4), 462-472. doi:10.1016/j.ccell.2015.02.015

Ruhland, M. K., Roberts, E. W., Cai, E., Mujal, A. M., Marchuk, K., Beppler, C., et al. (2020). Visualizing Synaptic Transfer of Tumor Antigens Among Dendritic Cells. Cancer Cell 37 (6), 786-799.e5. doi:10.1016/j.ccell.2020.05.002

Sallusto, F., and Lanzavecchia, A. (1994). Efficient Presentation of Soluble Antigen by Cultured Human Dendritic Cells Is Maintained by Granulocyte/ Macrophage Colony-Stimulating Factor Plus Interleukin 4 and Downregulated by Tumor Necrosis Factor Alpha. J. Exp. Med. 179 (4), 1109-1118. doi:10.1084/jem.179.4.1109

Salmon, H., Idoyaga, J., Rahman, A., Leboeuf, M., Remark, R., Jordan, S., et al. (2016). Expansion and Activation of CD103 + Dendritic Cell Progenitors at the
Tumor Site Enhances Tumor Responses to Therapeutic PD-L1 and BRAF Inhibition. Immunity 44 (4), 924-938. doi:10.1016/j.immuni.2016.03.012

Sanford, D. E., Belt, B. A., Panni, R. Z., Mayer, A., Deshpande, A. D., Carpenter, D., et al. (2013). Inflammatory Monocyte Mobilization Decreases Patient Survival in Pancreatic Cancer: A Role for Targeting the CCL2/CCR2 Axis. Clin. Cancer Res. 19 (13), 3404-3415. doi:10.1158/1078-0432.CCR-13-0525

Sarrazin, S., Mossadegh-Keller, N., Fukao, T., Aziz, A., Mourcin, F., Vanhille, L., et al. (2009). MafB Restricts M-CSF-dependent Myeloid Commitment Divisions of Hematopoietic Stem Cells. Cell 138 (2), 300-313. doi:10.1016/ j.cell.2009.04.057

Sasmono, R. T., Oceandy, D., Pollard, J. W., Tong, W., Pavli, P., Wainwright, B. J., et al. (2003). A Macrophage colony-stimulating Factor Receptor-green Fluorescent Protein Transgene Is Expressed throughout the Mononuclear Phagocyte System of the Mouse. Blood 101 (3), 1155-1163. doi:10.1182/ blood-2002-02-0569

Satthaporn, S., Robins, A., Vassanasiri, W., El-Sheemy, M., Jibril, J. A., Clark, D., et al. (2004). Dendritic Cells Are Dysfunctional in Patients with Operable Breast Cancer. Cancer Immunol. ImmunotherapyImmunotherapy 53 (6), 510-518. doi:10.1007/s00262-003-0485-5

Schlitzer, A., McGovern, N., and Ginhoux, F. (2015). Dendritic Cells and Monocyte-Derived Cells: Two Complementary and Integrated Functional Systems. Semin. Cel Develop. Biol. 41 (maio), 9-22. doi:10.1016/ j.semcdb.2015.03.011

Schmidts, A., Marsh, L. C., Srivastava, A. A., Bouffard, A. A., Boroughs, A. C., Scarfo, I., et al. (2020). Cell-Based Artificial APC Resistant to Lentiviral Transduction for Efficient Generation of CAR-T Cells from Various Cell Sources. J. Immunother. Cancer 8 (2), e000990. doi:10.1136/jitc-2020-000990 Scholl, S. M., Lidereau, R., de la Rochefordière, A., Cohen-Solal Le-Nir, C., Mosseri, V., Noguès, C., et al. (1996). Circulating Levels of the Macrophage Colony Stimulating Factor CSF-1 in Primary and Metastatic Breast Cancer Patients. A Pilot Study. Breast Cancer Res. Tr 39 (3), 275-283. doi:10.1007/BF01806155

Segura, E., Amigorena, S., and Théry, C. (2005). Mature Dendritic Cells Secrete Exosomes with Strong Ability to Induce Antigen-specific Effector Immune Responses. Blood Cell Mol. Dis. 35 (2), 89-93. doi:10.1016/j.bcmd.2005.05.003

Segura, E., Touzot, M., Bohineust, A., Cappuccio, A., Chiocchia, G., Hosmalin, A., et al. (2013). Human Inflammatory Dendritic Cells Induce Th17 Cell Differentiation. Immunity 38 (2), 336-348. doi:10.1016/j.immuni.2012.10.018

Serbina, N. V., Jia, T., Hohl, T. M., and Pamer, E. G. (2008). Monocyte-Mediated Defense against Microbial Pathogens. Annu. Rev. Immunol. 26 (1), 421-452. doi:10.1146/annurev.immunol.26.021607.090326

Shah, N. N., Johnson, B. D., Schneider, D., Zhu, F., Szabo, A., Keever-Taylor, C. A., et al. (2020). Bispecific Anti-CD20, Anti-CD19 CAR T Cells for Relapsed B Cell Malignancies: A Phase 1 Dose Escalation and Expansion Trial. Nat. Med. 26 (10), 1569-1575. doi:10.1038/s41591-020-1081-3

Sharma, A., Seow, J. J. W., Dutertre, C.-A., Pai, R., Blériot, C., Mishra, A., et al. (2020). Onco-Fetal Reprogramming of Endothelial Cells Drives Immunosuppressive Macrophages in Hepatocellular Carcinoma. Cell 183 (2), 377-394.e21. doi:10.1016/j.cell.2020.08.040

Shigeta, K., Kosaka, T., Kitano, S., Yasumizu, Y., Miyazaki, Y., Mizuno, R., et al. (2016). High Absolute Monocyte Count Predicts Poor Clinical Outcome in Patients with Castration-Resistant Prostate Cancer Treated with Docetaxel Chemotherapy. Ann. Surg. Oncol. 23 (12), 4115-4122. doi:10.1245/s10434-0165354-5

Simonetta, F., Alvarez, M., and Negrin, R. S. (2017). Natural Killer Cells in GraftVersus-Host-Disease after Allogeneic Hematopoietic Cell Transplantation. Front. Immunol. 8 (abril), 465. doi:10.3389/fimmu.2017.00465

Sisirak, V., Faget, J., Gobert, M., Goutagny, N., Vey, N., Treilleux, I., et al. (2012). Impaired IFN- $\alpha$ Production by Plasmacytoid Dendritic Cells Favors Regulatory T-Cell Expansion that May Contribute to Breast Cancer Progression. Cancer Res. 72 (20), 5188-5197. doi:10.1158/0008-5472.CAN-11-3468

Sisirak, V., Vey, N., Goutagny, N., Renaudineau, S., Malfroy, M., Thys, S., et al. (2013). Breast Cancer-Derived Transforming Growth Factor- $\beta$ and Tumor Necrosis Factor- $\alpha$ Compromise Interferon- $\alpha$ Production by Tumor-Associated Plasmacytoid Dendritic Cells. Int. J. Cancer 133 (3), 771-778. doi:10.1002/ ijc. 28072

Spranger, S., Dai, D., Horton, B., and Gajewski, T. F. (2017). Tumor-Residing Batf3 Dendritic Cells Are Required for Effector T Cell Trafficking and Adoptive T Cell Therapy. Cancer Cell 31 (5), 711-723.e4. doi:10.1016/j.ccell.2017.04.003 
Steidl, C., Lee, T., Shah, S. P., Farinha, P., Han, G., Nayar, T., et al. (2010). TumorAssociated Macrophages and Survival in Classic Hodgkin's Lymphoma. N. Engl. J. Med. 362 (10), 875-885. doi:10.1056/NEJMoa0905680

Stone, S. C., Rossetti, R. A. M., Bolpetti, A., Boccardo, E., de Araujo Souza, P. S., and Lepique, A. P. (2014). HPV16-Associated Tumors Control Myeloid Cell Homeostasis in Lymphoid Organs, Generating a Suppressor Environment for T Cells. J. Leukoc. Biol. 96 (4), 619-631. doi:10.1189/jlb.3A0513-282R

Stroh, T., Erben, U., Kühl, A. A., Zeitz, M., and Siegmund, B. (2010). Combined Pulse Electroporation - A Novel Strategy for Highly Efficient Transfection of Human and Mouse Cells. PLoS ONE 5 (3), e9488. doi:10.1371/ journal.pone. 0009488

Takahashi, R., Jjichi, H., Sano, M., Miyabayashi, K., Mohri, D., Kim, J., et al. (2020). Soluble VCAM-1 Promotes Gemcitabine Resistance via Macrophage Infiltration and Predicts Therapeutic Response in Pancreatic Cancer. Sci. Rep. 10 (1), 21194. doi:10.1038/s41598-020-78320-3

Tang, M., Diao, J., Gu, H., Khatri, I., Zhao, J., and Cattral, M. S. (2015). Toll-like Receptor 2 Activation Promotes Tumor Dendritic Cell Dysfunction by Regulating IL-6 and IL-10 Receptor Signaling. Cel Rep. 13 (12), 2851-2864. doi:10.1016/j.celrep.2015.11.053

Tang-Huau, T.-L., Gueguen, P., Goudot, C., Durand, M., Bohec, M., Baulande, S., et al. (2018). Human In Vivo-Generated Monocyte-Derived Dendritic Cells and Macrophages Cross-Present Antigens through a Vacuolar Pathway. Nat. Commun. 9 (1), 2570. doi:10.1038/s41467-018-04985-0

Taylor, P. R., and Gordon, S. (2003). Monocyte Heterogeneity and Innate Immunity. Immunity 19 (1), 2-4. doi:10.1016/S1074-7613(03)00178-X

Thistlethwaite, F. C., Gilham, D. E., Guest, R. D., Rothwell, D. G., Pillai, M., Burt, D. J., et al. (2017). The Clinical Efficacy of First-Generation Carcinoembryonic Antigen (CEACAM5)-specific CAR T Cells Is Limited by Poor Persistence and Transient Pre-conditioning-dependent Respiratory Toxicity. Cancer Immunol. Immunother. 66 (11), 1425-1436. doi:10.1007/s00262-017-2034-7

Thomachot, M. C. c., Bendriss-Vermare, N., Massacrier, C., Biota, C., Treilleux, I., Goddard, S., et al. (2004). Breast Carcinoma Cells Promote the Differentiation of CD34+ Progenitors towards 2 Different Subpopulations of Dendritic Cells with CD1ahighCD86?Langerin- and CD1a+CD86+Langerin+ Phenotypes. Int. J. Cancer 110 (5), 710-720. doi:10.1002/ijc.20146

Torroella-Kouri, M., Rodríguez, D., and Caso, R. (2013). Alterations in Macrophages and Monocytes from Tumor-Bearing Mice: Evidence of Local and Systemic Immune Impairment. Immunol. Res. 57 (1-3), 86-98. doi:10.1007/s12026-013-8438-3

Treilleux, I., Blay, J.-Y., Bendriss-Vermare, N., Ray-Coquard, I., Bachelot, T., Guastalla, J.P., et al. (2004). Dendritic Cell Infiltration and Prognosis of Early Stage Breast Cancer. Clin. Cancer Res. 10 (22), 7466-7474. doi:10.1158/1078-0432.CCR-04-0684

Trovato, R., Fiore, A., Sartori, S., Canè, S., Giugno, R., Cascione, L., et al. (2019). Immunosuppression by Monocytic Myeloid-Derived Suppressor Cells in Patients with Pancreatic Ductal Carcinoma Is Orchestrated by STAT3. J. Immunother. Cancer 7 (1), 255. doi:10.1186/s40425-019-0734-6

Truxova, I., Kasikova, L., Hensler, M., Skapa, P., Laco, J., Pecen, L., et al. (2018). Mature Dendritic Cells Correlate with Favorable Immune Infiltrate and Improved Prognosis in Ovarian Carcinoma Patients. J. Immunother. Cancer 6 (1), 139. doi:10.1186/s40425-018-0446-3

van Furth, R., and Cohn, Z. A. (1968). The Origin and Kinetics of Mononuclear Phagocytes. J. Exp. Med. 128 (3), 415-435. doi:10.1084/jem.128.3.415

Villani, A.-C., Satija, R., Reynolds, G., Sarkizova, S., Shekhar, K., Fletcher, J., et al. (2017). Single-Cell RNA-Seq Reveals New Types of Human Blood Dendritic Cells, Monocytes, and Progenitors. Science 356 (6335), eaah4573. doi:10.1126/ science.aah4573

Villar, J., and Segura, E. (2020). Decoding the Heterogeneity of Human Dendritic Cell Subsets. Trends Immunol. 41 (12), 1062-1071. doi:10.1016/j.it.2020.10.002

Waldman, A. D., Fritz, J. M., and Lenardo, M. J. (2020). A Guide to Cancer Immunotherapy: From T Cell Basic Science to Clinical Practice. Nat. Rev. Immunol. 20 (11), 651-668. doi:10.1038/s41577-020-0306-5

Watchmaker, P. B., Lahl, K., Lee, M., Baumjohann, D., Morton, J., KimKim, S. J., et al. (2014). Comparative Transcriptional and Functional Profiling Defines Conserved Programs of Intestinal DC Differentiation in Humans and Mice. Nat. Immunol. 15 (1), 98-108. doi:10.1038/ni.2768

Wculek, S. K., Amores-Iniesta, J., Conde-Garrosa, R., Khouili, S. C., Melero, I., and Sancho, D. (2019). Effective Cancer Immunotherapy by Natural Mouse
Conventional Type-1 Dendritic Cells Bearing Dead Tumor Antigen. J. Immunotherapy Cancer 7 (1), 100. doi:10.1186/s40425-019-0565-5

Wculek, S. K., Cueto, F. J., Mujal, A. M., Melero, I., Krummel, M. F., and Sancho, D. (2020). Dendritic Cells in Cancer Immunology and Immunotherapy. Nat. Rev. Immunol. 20 (1), 7-24. doi:10.1038/s41577-019-0210-Z

Wilgenhof, S., Corthals, J., Heirman, C., van Baren, N., Lucas, S., Kvistborg, P., et al. (2016). Phase II Study of Autologous Monocyte-Derived MRNA Electroporated Dendritic Cells (TriMixDC-MEL) Plus Ipilimumab in Patients with Pretreated Advanced Melanoma. J. Clin. Oncol. 34 (12), 1330-1338. doi:10.1200/JCO.2015.63.4121

Wong, K. L., Tai, J. J.-Y., Wong, W.-C., Han, H., Sem, X., Yeap, W.-H., et al. (2011). Hao Han, Xiaohui Sem, Wei-Hseun Yeap, Philippe Kourilsky, and Siew-Cheng WongGene Expression Profiling Reveals the Defining Features of the Classical, Intermediate, and Nonclassical Human Monocyte Subsets. Blood 118 (5), e16-e31. doi:10.1182/blood-2010-12-326355

Wong, K. L., Yeap, W. H., Tai, J. J. Y., Ong, S. M., Dang, T. M., and Wong, S. C. (2012). The Three Human Monocyte Subsets: Implications for Health and Disease. Immunol. Res. 53 (1-3), 41-57. doi:10.1007/s12026-012-8297-3

Wu, W.-C., Sun, H.-W., Chen, H.-T., Liang, J., Yu, X.-J., Wu, C., et al. (2014). Circulating Hematopoietic Stem and Progenitor Cells Are Myeloid-Biased in Cancer Patients. Proc. Natl. Acad. Sci. 111 (11), 4221-4226. doi:10.1073/pnas.1320753111

Xie, G., Dong, H., Liang, Y., HamHam, J. D., Rizwan, R., and Chen, J. (2020). CARNK Cells: A Promising Cellular Immunotherapy for Cancer. EBioMedicine 59 (setembro), 102975. doi:10.1016/j.ebiom.2020.102975

Yang, X., Feng, W., Wang, R., Yang, F., Wang, L., Chen, S., et al. (2018). Repolarizing Heterogeneous Leukemia-Associated Macrophages with More M1 Characteristics Eliminates Their Pro-leukemic Effects. OncoImmunology 7 (4), e1412910. doi:10.1080/2162402X.2017.1412910

Zhang, D. K. Y., Cheung, A. S., and Mooney, D. J. (2020). Activation and Expansion of Human $\mathrm{T}$ Cells Using Artificial Antigen-Presenting Cell Scaffolds. Nat. Protoc. 15 (3), 773-798. doi:10.1038/s41596-019-0249-0

Zhang, L., Tian, L., Dai, X., Yu, H., Wang, J., Lei, A., et al. (2020). Pluripotent Stem Cell-Derived CAR-Macrophage Cells with Antigen-dependent Anti-cancer Cell Functions. J. Hematol. Oncol. 13 (1), 153. doi:10.1186/s13045-020-00983-2

Zhang, M., Huang, L., Ding, G., Huang, H., Cao, G., Sun, X., et al. (2020). Interferon Gamma Inhibits CXCL8-CXCR2 axis Mediated Tumor-Associated Macrophages Tumor Trafficking and Enhances Anti-PD1 Efficacy in Pancreatic Cancer. J. Immunother. Cancer 8 (1), e000308. doi:10.1136/jitc-2019-000308

Zhang, W., Liu, L., Su, H., Liu, Q., Shen, J., Dai, H., et al. (2019). Chimeric Antigen Receptor Macrophage Therapy for Breast Tumours Mediated by Targeting the Tumour Extracellular Matrix. Br. J. Cancer 121 (10), 837-845. doi:10.1038/s41416019-0578-3

Zhu, Y., Herndon, J. M., Sojka, D. K., Kim, K.-W., Knolhoff, B. L., Zuo, C., et al. (2017). Tissue-Resident Macrophages in Pancreatic Ductal Adenocarcinoma Originate from Embryonic Hematopoiesis and Promote Tumor Progression. Immunity 47 (2), 323-338.e6. doi:10.1016/j.immuni.2017.07.014

Ziegler-Heitbrock, L., Ancuta, P., Crowe, S., Dalod, M., Grau, V., Hart, D. N., et al. (2010). Nomenclature of Monocytes and Dendritic Cells in Blood. Blood 116 (16), e74-e80. doi:10.1182/blood-2010-02-258558

Conflict of Interest: The authors declare that the research was conducted in the absence of any commercial or financial relationships that could be construed as a potential conflict of interest.

Publisher's Note: All claims expressed in this article are solely those of the authors and do not necessarily represent those of their affiliated organizations, or those of the publisher, the editors and the reviewers. Any product that may be evaluated in this article, or claim that may be made by its manufacturer, is not guaranteed or endorsed by the publisher.

Copyright $\odot 2021$ Ramos, Couto, Oliveira, Klinger, Braga, Rego, Barbuto and Rocha. This is an open-access article distributed under the terms of the Creative Commons Attribution License (CC BY). The use, distribution or reproduction in other forums is permitted, provided the original author(s) and the copyright owner(s) are credited and that the original publication in this journal is cited, in accordance with accepted academic practice. No use, distribution or reproduction is permitted which does not comply with these terms. 